\title{
Dimensions and aspect ratios of natural ice crystals
}

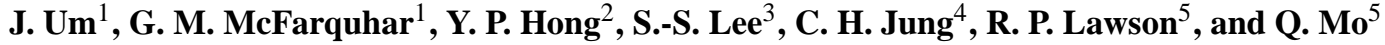 \\ ${ }^{1}$ Department of Atmospheric Sciences, University of Illinois at Urbana-Champaign, Urbana, Illinois, USA \\ ${ }^{2}$ Department of Computer Science, University of Illinois at Urbana-Champaign, Urbana, Illinois, USA \\ ${ }^{3}$ Earth System Science Interdisciplinary Center, College Park, Maryland, USA \\ ${ }^{4}$ Department of Health Management, Kyungin Women's University, Incheon, South Korea \\ ${ }^{5}$ SPEC Inc., Boulder, Colorado, USA \\ Correspondence to: J. Um (junum@illinois.edu)
}

Received: 10 October 2014 - Published in Atmos. Chem. Phys. Discuss.: 10 December 2014

Revised: 5 March 2015 - Accepted: 13 March 2015 - Published: 15 April 2015

\begin{abstract}
During the 2006 Tropical Warm Pool International Cloud Experiment (TWP-ICE) in the tropics, the 2008 Indirect and Semi-Direct Aerosol Campaign (ISDAC) in the Arctic, and the 2010 Small PARTicles In CirrUS (SPARTICUS) campaign at mid-latitudes, high-resolution images of ice crystals were recorded by a Cloud Particle Imager at temperatures $(T)$ between -87 and $0{ }^{\circ} \mathrm{C}$. The projected maximum dimension $\left(D^{\prime}\right)$, length $\left(L^{\prime}\right)$, and width $\left(W^{\prime}\right)$ of pristine columns, plates, and component bullets of bullet rosettes were measured using newly developed software, the Ice Crystal Ruler. The number of bullets in each bullet rosette was also measured. Column crystals were further distinguished as either horizontally oriented columns or columns with other orientations to eliminate any orientation effect on the measured dimensions. The dimensions and aspect ratios (AR, the dimension of the major axis divided by the dimension of the minor axis) of crystals were determined as functions of temperature, geophysical location, and type of cirrus.

Dimensions of crystals generally increased with temperature. Columns and bullets had larger dimensions (i.e., $W^{\prime}$ ) of the minor axis (i.e., $a$ axis) for a given dimension (i.e., $D^{\prime}$ or $L^{\prime}$ ) of the major axis (i.e., $c$ axis), and thus smaller AR, as $T$ increased, whereas this trend did not occur for plate crystals. The average number of branches in bullet rosettes was $5.50 \pm 1.35$ during three campaigns and $6.32 \pm 1.34$ $(5.46 \pm 1.34 ; 4.95 \pm 1.01)$ during TWP-ICE (SPARTICUS; ISDAC). The AR of bullets increased with the number of branches in bullet rosettes. Most dimensions of crystals and ARs of columnar crystals measured during SPARTICUS were larger than those measured during TWP-ICE and ISDAC at $-67<T<-35^{\circ} \mathrm{C}$ and at $-40<T<-15^{\circ} \mathrm{C}$, re-
\end{abstract}

spectively. The relative occurrence of varying pristine habits depended strongly on cirrus type (i.e., anvil or non-anvil clouds), with plates especially occurring more frequently in anvils. The $L-W$ relationships of columns derived using current data exhibited a strong dependence on temperature; similar relationships determined in previous studies were within the range of the current data.

\section{Introduction}

The impacts of ice clouds on the energy budget of the Earth and their representation in climate models have been identified as important and unsolved problems (IPCC, 2013). Ice clouds consist almost exclusively of non-spherical ice crystals with various shapes (i.e., habits) and sizes (e.g., Liou, 1986). To determine the influences of ice clouds on solar and infrared radiation as required for numerical models and remote sensing retrievals, knowledge of single-scattering properties of ice crystals is required (e.g., Fu, 1996, 2007; McFarquhar et al., 2002; Baum et al., 2011; Baran, 2012; DeVore et al., 2012; Yang et al., 2013; Yi et al., 2013; Um and McFarquhar, 2013; Cole et al., 2014; van Diedenhoven et al., 2014a).

The fundamental building blocks of the most common ice crystal habits are hexagonal prisms (i.e., hexagonal columns and plates) because of the hexagonal lattice structure of water molecules in an ice crystal. The other common habit frequently found in cirrus is a bullet rosette and its basic component (i.e., branch or arm) is also a hexagonal prism. Since initial work that identified crystal shapes using in situ ob- 
servations of ice clouds (e.g., Weickmann, 1948, and studies summarized by Dowling and Radke, 1990, and by Heymsfield and McFarquhar, 2002), much effort has been devoted to quantify the microphysical and scattering properties of ice crystals. One important finding is that ambient atmospheric conditions (e.g., temperature and humidity) govern the growth and morphological properties of ice crystals (e.g., aufm Kampe et al., 1951; Lamb and Scott, 1974; Gonda, 1980; Fukuta and Takahashi, 1999; Bacon et al., 2003; Bailey and Hallett, 2002, 2004, 2009, 2012; Korolev et al., 2004) upon which the corresponding scattering properties depend (e.g., Takano and Liou, 1995; Macke et al., 1996; Yang and Liou, 1998; Baran et al., 2001, 2005; Yang et al., 2005, 2013; Um and McFarquhar, 2007, 2009, 2011).

To define ice crystal shapes and to calculate the corresponding single-scattering properties, dimensional information representing the morphology of ice crystals is required. Figure 1 shows the definitions of dimensions used to describe idealized models of ice crystals. A column (Fig. 1a) has a longer dimension called the length $(L)$ along its $c$ axis and a shorter perpendicular width $(W)$ along its $a$ axis, whereas $W$ is longer than $L$ for a plate (Fig. 1b). To define the structure of a bullet (Fig. 1c), which is the basic component of a bullet rosette, a tip height $(H)$ for the pyramid part of a bullet is required along with $L$ and $W$. For each ice crystal in Fig. 1, a maximum dimension $(D)$, the longest dimension within the ice crystal, is indicated by a long dashed line. In general, the aspect ratio (AR) of each ice crystal is defined as $W / L$ or $L / W$ for columns and plates, whereas it is $(H+L) / W$ or $W /(H+L)$ for bullets. Um and McFarquhar (2009) showed several definitions of AR that have been used in theoretical studies and in situ data analysis, which might impact derived scattering properties of ice crystals (Korolev and Isaac, 2003). In order to characterize aspect ratio in a form that is appropriate for numerical models, a power law relationship of the form $\alpha L^{\beta}$, where $\alpha$ and $\beta$ are constants determined empirically from observations, is typically used (e.g., Auer and Veal, 1970; Heymsfield, 1972; Hobbs et al., 1974; Davis, 1974; Mitchell and Arnott, 1994).

Accurate knowledge of dimensions and of $L-W$ relationships of ice crystals is important because it is used to construct shape models for calculating the single-scattering properties of ice crystals and for determining the microphysical properties of ice crystals, such as the cross-sectional area and fall velocity. Prior studies have shown that the assumed $L-W$ relationship impacts the single-scattering properties of ice crystals (Macke et al., 1996, Um and McFarquhar, 2007, 2009; Yang and Fu, 2009; van Diedenhoven et al., 2014a), satellite retrievals (Han et al., 1999), and numerical simulations (Fu, 2007; Sheridan et al., 2009; Sulia and Harrington, 2011; Dearden et al., 2012). In addition, new modeling approaches (e.g., Sulia and Harrington, 2011) that explicitly predict particle properties rather than using predefined ice categories as in traditional schemes require statistical databases of $L$ and $W$. Moreover, van Diedenhoven
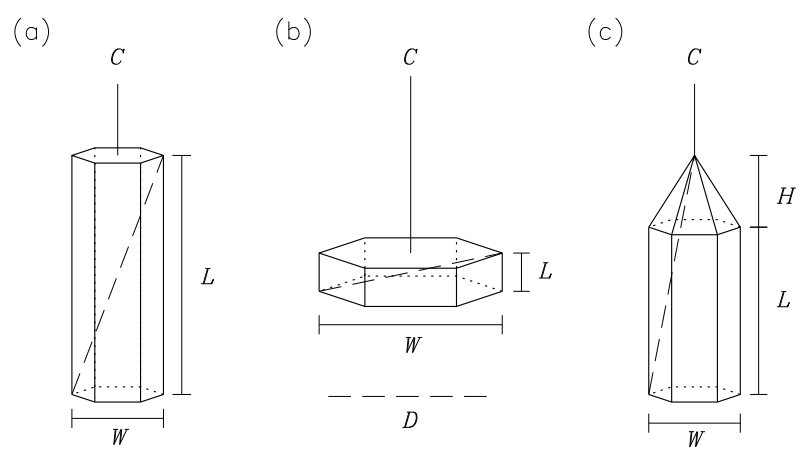

Figure 1. Idealized models of (a) column, (b) plate, and (c) bullet. The length $(L)$, width $(W)$, bullet tip height $(H)$, and $c$ axis are shown. A maximum dimension $(D)$ is indicated with a long-dash line.

et al. (2012; 2014b) developed an approach to remotely sense aspect ratios of ice crystal components, in addition to crystal roughness and asymmetry parameter, from aircraft- or satellite-based multi-directional polarization measurements. Therefore, not only are relationships between $L, W$, and AR needed, but also a database of measurements of $L, W$, and AR of individual crystals for comparison against model simulations and remote sensing retrievals.

Past studies have quantified the $L-W$ relationship or AR of natural ice crystals based on laboratory measurements and in situ data (e.g., Schaefer, 1947; Weickmann, 1948; Reynolds, 1952; Mason, 1953; Magono, 1954; Nakaya, 1954; Isono, 1959; Ono, 1969, 1970; Auer and Veal, 1970; Heymsfield, 1972; Hobbs et al., 1974; Davis, 1974; Goodman et al., 1989; Mitchell and Arnott, 1994; Walden et al., 2003; Baker and Lawson, 2006; Um and McFarquhar, 2007). However, most such work was based on a very limited number of measured crystals observed within a limited temperature range in a single geographic regime, except for the study of Baker and Lawson (2006). This paper considerably extends these past efforts by using a much larger number of ice crystals imaged in a variety of conditions and locations to determine what controls $L-W$ relationships and ARs of individual crystals. In particular, the dimensions of hexagonal prisms (i.e., columns and plates) and individual branches (i.e., bullets) of bullet rosettes were obtained from high-resolution ice crystal images recorded by the Cloud Particle Imager (CPI) during the 2006 Tropical Warm Pool International Cloud Experiment (TWP-ICE, May et al., 2008) in the tropics, the 2008 Indirect and Semi-Direct Aerosol Campaign (ISDAC, McFarquhar et al., 2011) in the Arctic, and the 2010 Small PARTicles In CirrUS (SPARTICUS, Zhang et al., 2013) campaign at mid-latitudes.

The paper is organized as follows. The $L-W$ relationships or ARs of ice crystals determined in previous studies are summarized in Sect. 2. In Sect. 3, the newly collected data are described and the methodology used to determine the dimensions of the imaged ice crystals is explained. In Sect. 4, 
the measured dimensions of the ice crystals and derived $L-$ $W$ relationships are shown as functions of temperature, habit, and geophysical location. A comparison between the derived $L-W$ relationships and those from previous studies is also shown in Sect. 4. The importance and new findings of this study are summarized in Sect. 5 .

\section{Prior $L-W$ relationships}

Different methods have been used to measure the dimensions upon which the $L-W$ relationships in Tables $1-3$ were based. Replicas of ice crystals have been collected at high-altitude observatories (e.g., Auer and Veal, 1970), using aircraft (e.g., Heymsfield, 1972; Hobbs et al., 1974), and at lower-altitude ground observatories (Hobbs et al., 1974), with dimensions subsequently measured by microscopes with up to 100 times magnification or through projection of magnified images of the replica on a screen. Alternatively, Kajikawa (1972) measured the dimensions of ice crystals using photographs of ice crystals taken at various orientations, whereas Mitchell and Arnott (1994) derived $L-W$ relations of bullets by matching the size and projected area relations based on the in situ observations of Arnott et al. (1994). Other studies, like that of Davis (1974), combined data from previous studies (Auer and Veal, 1970; Ono, 1970; Kajikawa, 1972; personal communication between R. L. D'Errico and C. I. Davis, 1973) to quantify $L-W$ relations for several crystal habits, whereas Mitchell and Arnott (1994) reanalyzed the dimensions of solid and hollow columns obtained in a warm $(-10<T<$ $-8^{\circ} \mathrm{C}$ ) growth environment (Auer and Veal, 1970) to determine a $L-W$ relationship.

Baker and Lawson (2006) took advantage of highresolution ice crystal images obtained by a CPI to measure crystal dimensions and derive $L-W$ relations of pristine columns in wave clouds. Um and McFarquhar (2007) also used crystal images obtained by a CPI to determine dimensions of bullets that were components of aggregates of bullet rosettes obtained in mid-latitude cirrus. Since the crystal images recorded by the CPI are silhouettes, projections of the randomly oriented three-dimensional crystal shapes, they further applied an iterative approach to simulate random orientations of the crystals, from which they derived a $L-W$ relationship for bullets.

As shown in Tables $1-3$, most of the $L-W$ relationships derived in previous studies were determined over a limited temperature range and using a relatively small number of samples. The numbers of samples shown in Tables 1-3 were estimated from the original figures in each study. In this study, previous $L-W$ relationships of ice crystals are compared against those newly derived based on the large data set analyzed here as functions of temperature, habit, and geophysical location.

\section{Data and methodology}

\subsection{Data set}

Ice crystals imaged by a CPI collected in three diverse geographic regimes (tropics, mid-latitudes, and Arctic) were used in this study to determine the dimensions and relation between $L$ and $W$ of columns, plates, and bullets. The CPI records images of cloud particles with high resolution $(2.3 \mu \mathrm{m})$ on a 1 million pixel charge coupled device. A $25 \mathrm{~ns}$ pulsed high-power laser is triggered when a cloud particle is detected in the sample volume by two lower powered particle detection lasers shining on photodiode detectors (Lawson et al., 2001). Due to the CPI's resolution, only particles larger than about $10 \mu \mathrm{m}$ are counted. In this study, dimensions of particles larger than $20 \mu \mathrm{m}$ were determined.

The tropical data were collected during the 2006 TWPICE. It was conducted between 12 January and 14 February 2006 in the region near Darwin $\left(12^{\circ} 27^{\prime} \mathrm{S}, 130^{\circ} 50^{\prime} \mathrm{E}\right)$, Northern Territory, Australia. TWP-ICE focused on the evolution of cloud systems, their environmental influences, and their growth from the initial convective cells through to decaying and self-maintaining cirrus. During TWP-ICE, the Scaled Composites Proteus aircraft made intensive airborne measurements in aged cirrus, fresh anvils, and cirrus of unknown origin. Table 4 summarizes the type of the sampled cirrus, the environmental conditions under which the ice crystals were measured, and the numbers of analyzed crystals for each TWP-ICE flight for which CPI images were analyzed.

Between January and June 2010, the SPARTICUS campaign was conducted over the Department of Energy (DOE) Atmospheric Radiation Measurement (ARM) program's Southern Great Plains site in Oklahoma $\left(36^{\circ} 36^{\prime} \mathrm{N}\right.$, $\left.97^{\circ} 29^{\prime} \mathrm{W}\right)$. The overarching goal of SPARTICUS was to determine the impact of small ice crystals on the microphysical and radiative properties of mid-latitude cirrus, to quantify the dependence of the evolution of cirrus properties on cloudscale dynamical processes, and to test the level of complexity required in cloud property retrieval algorithms. During SPARTICUS, a CPI on the Stratton Park Engineering Company (SPEC) Inc. Learjet 25 aircraft recorded images of ice crystals; the images analyzed for this study are summarized in Table 5. Crystals imaged in ice clouds with synoptic, orographic origin, and anvil cirrus were analyzed.

During ISDAC in April 2008, a CPI on the National Research Council (NRC) of Canada Convair 580 aircraft recorded images of cloud particles. Although the main objectives of ISDAC centered on understanding the interactions of clouds and aerosols in low-level mixed-phase clouds, transits of the NRC Convair 580 between Fairbanks $\left(64^{\circ} 50^{\prime} \mathrm{N}\right.$, $\left.147^{\circ} 43^{\prime} \mathrm{W}\right)$ and Barrow $\left(71^{\circ} 17^{\prime} \mathrm{N}, 156^{\circ} 45^{\prime} \mathrm{W}\right)$ at cirrus levels allowed measurements in high-level ice clouds on 6 different days. Table 6 lists the numbers of ice crystals analyzed for this study, and the conditions under which the images were obtained. 
Table 1. Summary of $L-W$ relationships of column crystals from previous studies: AV70 (Auer and Veal, 1970), HF72 (Heymsfield, 1972), H74 (Hobbs et al., 1974), D74 (Davis, 1974), MA94 (Mitchell and Arnott, 1994), and BL06 (Baker and Lawson, 2006). Ice crystal habit classification (Magono and Lee, 1966) is also shown when the original work indicated habit. NA indicates that corresponding information is not available.

\begin{tabular}{|c|c|c|c|c|}
\hline Source & Habit & $L-W$ relationship $(\mu \mathrm{m})$ & $T\left({ }^{\circ} \mathrm{C}\right)$ & $\begin{array}{l}\text { Number } \\
\text { of samples }\end{array}$ \\
\hline AV70 & $\begin{array}{l}\text { Solid (C1e) and } \\
\text { hollow column }(\mathrm{C} 1 \mathrm{f})\end{array}$ & $\begin{array}{l}W=-8.479+1.002 L-0.00234 L^{2}(L \leq 200) \\
W=11.3 L^{0.414}(L>200)\end{array}$ & $\begin{array}{l}-10< \\
T<-8 \\
T<-20\end{array}$ & $<220$ \\
\hline HF72 & Column & $\begin{array}{l}W=0.5 L(L \leq 200) \\
W=11.3 L^{0.414}(L>200)\end{array}$ & $\begin{array}{l}-20< \\
T<-18\end{array}$ & $<240$ \\
\hline H74_1 & $\begin{array}{l}\text { Sheaths and } \\
\text { long solid column }\end{array}$ & $\begin{array}{l}\ln W=-0.6524+1.32 \ln L-0.0846(\ln L)^{2} \\
(100<L<3200)\end{array}$ & NA & $<130$ \\
\hline H74_2 & $\begin{array}{l}\text { Solid and hollow } \\
\text { column }\end{array}$ & $\begin{array}{l}\ln W=1.384+0.2396 \ln L+0.0507(\ln L)^{2} \\
(30<L<1200)\end{array}$ & NA & $<330$ \\
\hline $\begin{array}{l}\text { D74_1 } \\
\text { D74_2 }\end{array}$ & Solid column (C1e) & $\begin{array}{l}W=0.85 L^{0.958}(L / W \leq 2 \& 10<L<1000) \\
W=0.51 L^{0.927}(L / W>2 \& 10<L<1000)\end{array}$ & NA & $<220$ \\
\hline $\begin{array}{l}\text { D74_3 } \\
\text { D74_4 }\end{array}$ & Hollow column (C1f) & $\begin{array}{l}W=1.14 L^{0.892}(L / W \leq 2 \& 10<L<1000) \\
W=0.50 L^{0.930}(L / W>2 \& 10<L<1000)\end{array}$ & NA & $<270$ \\
\hline MA94 & $\begin{array}{l}\text { Solid }(\mathrm{C} 1 \mathrm{e}) \text { and } \\
\text { hollow column }(\mathrm{C} 1 \mathrm{f})\end{array}$ & $\begin{array}{l}W=0.7 L^{1.0}(L<100) \\
W=6.96 L^{0.5}(100 \leq L<1000)\end{array}$ & $\begin{array}{l}-10< \\
T<-8\end{array}$ & $<175$ \\
\hline BL06 & $\begin{array}{l}\text { Solid (C1e) and } \\
\text { hollow column (C1f) }\end{array}$ & $W=0.3535 L^{1.0357}(20<L<700)$ & $\begin{array}{l}-60< \\
T<-17\end{array}$ & 456 \\
\hline
\end{tabular}

Table 2. Summary of $L-W$ relationships of plate crystals from previous studies: AV70 (Auer and Veal, 1970), H74 (Hobbs et al., 1974), and D74 (Davis, 1974). Ice crystal habit classification (Magono and Lee, 1966) is also shown when the original work indicated habit. NA indicates that corresponding information is not available.

\begin{tabular}{|c|c|c|c|c|}
\hline Source & Habit & $L-W$ relationship $(\mu \mathrm{m})$ & $T\left({ }^{\circ} \mathrm{C}\right)$ & $\begin{array}{l}\text { Number } \\
\text { of samples }\end{array}$ \\
\hline AV70 & Hexagonal plate (P1a) & $L=2.020 W^{0.449}(W>20)$ & $\begin{array}{l}-13< \\
T< \\
-10, \\
-20< \\
T<-17\end{array}$ & $<140$ \\
\hline AV70 & $\begin{array}{l}\text { Solid thick plate }(\mathrm{C} 1 \mathrm{~g}) \\
\text { Thick plate of skeleton form }(\mathrm{C} 1 \mathrm{~h})\end{array}$ & $L=0.402 W^{1.018}(20<W<500)$ & $\begin{array}{l}-11< \\
T< \\
-9.5, \\
-20< \\
T< \\
-18.5\end{array}$ & $<120$ \\
\hline $\mathrm{H} 74$ & Hexagonal plate & $\begin{array}{l}L=99.17-37.49 \ln W+3.844(\ln W)^{2} \\
(80<W<2000)\end{array}$ & $\begin{array}{l}-17< \\
T<-12\end{array}$ & $<90$ \\
\hline D74 & Hexagonal plate (P1a) & $L=1.78 W^{0.475}(10<W<3000)$ & NA & $<180$ \\
\hline D74 & $\mathrm{P} 1 \mathrm{~b}$ & $L=2.14 W^{0.423}(10<W<2000)$ & NA & $<80$ \\
\hline D74 & P1c & $L=2.18 W^{0.415}(10<W<1500)$ & NA & $<200$ \\
\hline D74 & Solid thick plate $(\mathrm{C} 1 \mathrm{~g})$ & $L=1.07 W^{0.778}(10<W<1000)$ & NA & $<290$ \\
\hline
\end{tabular}

During all three campaigns, the DOE CPI version 2.0 was used to record images of ice crystals. Thus, there is no effect of varying image quality as a function of the version of the CPI used (McFarquhar et al., 2013). In this study, the dimensions of $11383(1977 ; 6728 ; 2678)$ columns and of 3936
$(2088 ; 1500 ; 348)$ plates imaged in situ by the CPI were determined; the numbers in parentheses indicate the number of each habit analyzed for each field project (TWP-ICE; SPARTICUS; ISDAC). In addition, a total of 7189 (751; 5677; 761 ) bullet rosettes were analyzed, with the dimensions of 
Table 3. Summary of $L-W$ relationships of bullet crystals from previous studies: HF72 (Heymsfield, 1972), MA94 (Mitchell and Arnott, 1994), and UM07 (Um and McFarquhar, 2007). NA indicates that corresponding information is not available.

\begin{tabular}{llllr}
\hline Source & Habit & $L-W$ relationship $(\mu \mathrm{m})$ & $T\left({ }^{\circ} \mathrm{C}\right)$ & $\begin{array}{r}\text { Number } \\
\text { of samples }\end{array}$ \\
\hline HF72 & Bullet & $W=1.0993 L^{0.7856}(L \leq 300)$, & $-20<T<$ & $<410$ \\
& & $W=4.6900 L^{0.532}(L \geq 300)$ & -18 & NA \\
MA94 & Bullet & $W=2.3104 L^{0.63}(100 \leq L \leq 500)$ & NA & 403 \\
UM07 & Bullet & $W=7.14 L^{0.455}(100 \leq L \leq 600)$ & $-50<T<$ & \\
& & & -20 & \\
\hline
\end{tabular}

Table 4. Type of cirrus, minimum and maximum temperature for the crystals analyzed, and numbers of all crystals, all columns, horizontally oriented columns (HCOL), plates, and bullet rosettes (total number of branches, mean and standard deviation of the number of component branches per bullet rosette) indicated for each flight during TWP-ICE.

\begin{tabular}{|c|c|c|c|c|c|c|}
\hline \multirow[t]{2}{*}{ Flight date } & \multirow[t]{2}{*}{ Type of cirrus } & \multirow[t]{2}{*}{$T\left({ }^{\circ} \mathrm{C}\right)$} & \multicolumn{4}{|c|}{ Number of samples } \\
\hline & & & $\begin{array}{r}\text { Total } \\
\text { samples }\end{array}$ & $\begin{array}{l}\text { Column } \\
\text { (HCOL) }\end{array}$ & Plate & $\begin{array}{l}\text { Bullet rosette } \\
\text { (no. of branches) }\end{array}$ \\
\hline 0125 & Aged cirrus & $-70.2 \leq T \leq-51.4$ & 20356 & $294(80)$ & 20 & $74(432,5.8 \pm 1.1)$ \\
\hline 0127 & Aged cirrus & $-81.5 \leq T \leq-45.5$ & 60683 & $289(64)$ & 63 & $84(551,6.6 \pm 1.3)$ \\
\hline 0129 & Aged cirrus & $-74.5 \leq T \leq-37.7$ & 77389 & $299(54)$ & 15 & $372(2488,6.7 \pm 1.3)$ \\
\hline 0202 & Anvil & $-67.8 \leq T \leq-18.3$ & 26684 & $282(75)$ & 143 & $90(559,6.2 \pm 1.3)$ \\
\hline 0206 & Anvil & $-73.1 \leq T \leq-40.2$ & 12798 & $271(78)$ & 439 & 0 \\
\hline 0210 & Anvil & $-78.7 \leq T \leq-40.5$ & 82494 & $394(46)$ & 1049 & 0 \\
\hline 0212 & Anvil & $-72.7 \leq T \leq-34.1$ & 60689 & $148(33)$ & 359 & $131(720,5.5 \pm 1.2)$ \\
\hline Total & & & 341093 & 1977 (430) & 2088 & $751(4750,6.3 \pm 1.3)$ \\
\hline
\end{tabular}

39527 (4750; 31007 ; 3770) component bullets obtained. The mean and standard deviation of the number of bullets in bullet rosettes were $6.3 \pm 1.3,5.5 \pm 1.3$, and $5.0 \pm 1.0$ for TWP-ICE, SPARTICUS, and ISDAC, respectively.

\subsection{Methodology}

The ice crystals imaged by the CPI were classified using the habit classification scheme described by Um and McFarquhar (2009). Ice crystals classified as columns, plates, and bullet rosettes were then visually inspected to restrict subsequent analysis to only well-defined or pristine shapes without riming from which dimensions could be unambiguously measured. The numbers of crystals whose dimensions were able to be measured are shown in Tables 4-6. Only $0.58 \%(0.61 ; 0.22 \%)$ of crystals were columns (plates; bullet rosettes) whose dimensions could be measured for TWPICE, whereas they were $0.79 \%(0.18 ; 0.67 \%)$ and $2.18 \%$ $(0.28 ; 0.62 \%)$ for SPARTICUS and ISDAC, respectively. In addition to crystals with irregular shapes, there were additional columns, plates, and bullet rosettes that are not included in study because the dimensions could not be unambiguously determined. The dominance of irregular particles was previously seen by Korolev et al. (1999), who found that over $90 \%$ of the total number of ice particles between 0 and $-45^{\circ} \mathrm{C}$ were not pristine in Arctic clouds. Nevertheless, the analysis of pristine ice crystals presented here is still important because pristine single crystals are fundamental building blocks of other habits and show base nucleated shapes before other growth, sublimation, aggregation, and riming processes occur, and hence offers information about nucleation and growth processes occurring in ice clouds.

In this study, the imaged columns included solid columns (C1e) and hollow columns (C1f), whereas the imaged plates included solid thick plates $(\mathrm{C} 1 \mathrm{~g})$, thick plates of skeleton form $(\mathrm{C} 1 \mathrm{~h})$, and hexagonal plates (P1a) based on the identification codes of Magono and Lee (1966). Other types of plates, such as crystals with sectorlike branches (P1b), crystals with broad branches (P1c), and stellar crystals (P1d), were not included due to large errors in measuring their dimensions. For bullets, both solid (C1c) and hollow bullets (C1d) as components of bullet rosettes were analyzed.

New software, henceforth called the Ice Crystal Ruler (ICRuler), which measures the dimensions of ice crystal images, was developed at the University of Illinois. Using this software, the maximum dimension, length, and width of the ice crystal images were determined. However, the images recorded by the CPI are neither three-dimensional shapes nor intersections of these shapes in a plane, but rather are silhouettes, projections of the randomly oriented three-dimensional crystal shapes on a plane. Thus, the measured maximum dimension, length, and width of ice crystals do not represent 
Table 5. Same as Table 4 but for SPARTICUS.

\begin{tabular}{|c|c|c|c|c|c|c|}
\hline \multirow[t]{2}{*}{ Flight date } & \multirow[t]{2}{*}{ Type of cirrus } & \multirow[t]{2}{*}{$T\left({ }^{\circ} \mathrm{C}\right)$} & \multicolumn{4}{|c|}{ Number of samples } \\
\hline & & & $\begin{array}{r}\text { Total } \\
\text { samples }\end{array}$ & $\begin{array}{l}\text { Column } \\
\text { (HCOL) }\end{array}$ & Plate & $\begin{array}{r}\text { Bullet rosette } \\
\text { (no. of branches) }\end{array}$ \\
\hline 0119A & Synoptic & $-56.0 \leq T \leq-18.8$ & 62501 & $619(168)$ & 38 & $199(1071,5.4 \pm 1.1)$ \\
\hline $0120 \mathrm{~A}$ & Synoptic & $-59.3 \leq T \leq-43.3$ & 26865 & $648(166)$ & 48 & $592(3489,5.9 \pm 1.2)$ \\
\hline 0120B & Synoptic & $-58.1 \leq T \leq-11.6$ & 38714 & $436(96)$ & 30 & $318(1817,5.7 \pm 1.3)$ \\
\hline 0211B & Synoptic & $-47.8 \leq T \leq-31.5$ & 16873 & $214(45)$ & 14 & $576(3495,6.1 \pm 1.3)$ \\
\hline 0322A & Orographic & $-40.1 \leq T \leq-20.6$ & 13795 & $126(34)$ & 11 & $234(1147,4.9 \pm 1.0)$ \\
\hline 0323A & Synoptic & $-60.4 \leq T \leq-12.4$ & 7199 & $133(39)$ & 10 & $51(314,6.2 \pm 1.1)$ \\
\hline 0326A & Synoptic & $-54.2 \leq T \leq-5.9$ & 63913 & $609(200)$ & 91 & $604(2986,4.9 \pm 1.0)$ \\
\hline 0330A & Synoptic & $-60.2 \leq T \leq-26.8$ & 11178 & $120(38)$ & 14 & $105(696,6.6 \pm 1.1)$ \\
\hline 0330B & Synoptic & $-58.5 \leq T \leq-29.9$ & 18225 & $235(56)$ & 25 & $236(1206,5.1 \pm 1.1)$ \\
\hline 0401A & Synoptic & $-54.2 \leq T \leq-38.0$ & 28398 & $374(92)$ & 6 & $482(2825,5.9 \pm 1.3)$ \\
\hline 0401B & Synoptic & $-51.6 \leq T \leq-21.7$ & 27984 & $164(31)$ & 31 & $216(1387,6.4 \pm 1.4)$ \\
\hline 0402A & Synoptic & $-59.3 \leq T \leq-18.6$ & 26873 & $209(60)$ & 11 & $41(271,6.6 \pm 1.0)$ \\
\hline 0411A & Synoptic & $-61.7 \leq T \leq-28.0$ & 31040 & $247(72)$ & 21 & $388(1931,6.0 \pm 1.2)$ \\
\hline 0411B & Orographic & $-33.7 \leq T \leq-25.3$ & 14244 & $86(27)$ & 18 & $111(494,4.5 \pm 0.8)$ \\
\hline 0414B & Anvil & $-52.5 \leq T \leq-30.6$ & 15309 & $193(58)$ & 76 & $109(566,5.2 \pm 1.3)$ \\
\hline 0416A & Synoptic & $-57.1 \leq T \leq-4.1$ & 35244 & $507(114)$ & 58 & $259(1184,4.6 \pm 1.2)$ \\
\hline 0416B & Synoptic & $-61 . \overline{5} \leq \bar{T} \leq 0.0$ & 52296 & $102(18)$ & 52 & $43(206,4.8 \pm 1.4)$ \\
\hline 0417A & Synoptic & $-66.1 \leq T \leq-4.6$ & 37758 & $229(31)$ & 58 & $204(1171,4.9 \pm 1.2)$ \\
\hline 0417B & Synoptic & $-60.7 \leq T \leq-5.0$ & 19011 & $138(13)$ & 5 & $235(1082,4.6 \pm 1.2)$ \\
\hline 0417C & Synoptic & $-37.9 \leq T \leq-8.8$ & 12491 & $51(14)$ & 38 & $18(87,4.8 \pm 1.2)$ \\
\hline 0422B & Anvil & $-62.7 \leq T \leq-10.2$ & 39461 & $110(29)$ & 131 & $7(38,5.4 \pm 1.1)$ \\
\hline 0424A & Anvil & $-48.3 \leq T \leq-14.3$ & 37176 & $190(36)$ & 210 & $136(708,5.2 \pm 1.2)$ \\
\hline 0428A & Synoptic & $-66.9 \leq T \leq-50.7$ & 24892 & $180(65)$ & 3 & $4(22,5.5 \pm 1.0)$ \\
\hline 0428B & Synoptic & $-65.8 \leq T \leq-31.3$ & 24414 & $295(86)$ & 12 & $104(595,5.7 \pm 1.2)$ \\
\hline 0429 & Synoptic & $-64.5 \leq T \leq-9.6$ & 9686 & $88(21)$ & 5 & $106(719,6.8 \pm 1.1)$ \\
\hline 0611A & Anvil & $-39.4 \leq T \leq-16.5$ & 11113 & $28(4)$ & 29 & $31(141,4.5 \pm 0.9)$ \\
\hline $0612 \mathrm{~A}$ & Anvil & $-49.5 \leq T \leq-15.7$ & 37986 & 67 (19) & 40 & $137(771,5.6 \pm 1.3)$ \\
\hline 0614 & Anvil & $-52.3 \leq T \leq-20.0$ & 35324 & $138(57)$ & 185 & $12(64,5.3 \pm 1.1)$ \\
\hline 0615A & Anvil & $-51.1 \leq T \leq-19.7$ & 47197 & $54(8)$ & 215 & $5(21,4.2 \pm 0.8)$ \\
\hline $0624 \mathrm{~A}$ & Anvil & $-50.6 \leq T \leq-28.9$ & 19374 & $138(24)$ & 15 & $78(503,6.4 \pm 1.2)$ \\
\hline Total & & & 846534 & $6728(1721)$ & 1500 & $5677(31007,5.5 \pm 1.3)$ \\
\hline
\end{tabular}

Table 6. Same as Table 4 but for ISDAC.

\begin{tabular}{|c|c|c|c|c|c|c|}
\hline \multirow[t]{2}{*}{ Flight date } & \multirow[t]{2}{*}{ Type of cirrus } & \multirow[t]{2}{*}{$T\left({ }^{\circ} \mathrm{C}\right)$} & \multicolumn{4}{|c|}{ Number of samples } \\
\hline & & & $\begin{array}{r}\text { Total } \\
\text { samples }\end{array}$ & $\begin{array}{l}\text { Column } \\
\text { (HCOL) }\end{array}$ & Plate & $\begin{array}{r}\text { Bullet rosette } \\
\text { (no. of branches) }\end{array}$ \\
\hline 0404 & Synoptic & $-39.4 \leq T \leq-1.0$ & 31601 & $745(272)$ & 84 & $45(260,5.8 \pm 1.0)$ \\
\hline 0405 & Synoptic & $-38.3 \leq T \leq-14.0$ & 25112 & $325(91)$ & 50 & $21(116,5.5 \pm 0.8)$ \\
\hline 0413 & Synoptic & $-33.7 \leq T \leq-16.4$ & 3864 & $72(13)$ & 9 & $37(227,6.1 \pm 1.5)$ \\
\hline 0419 & Synoptic & $-33.5 \leq T \leq-8.5$ & 1019 & 409 (121) & 19 & $304(1455,4.8 \pm 1.0)$ \\
\hline 0425 & Synoptic & $-36.0 \leq T \leq-4.0$ & 43811 & $634(175)$ & 126 & $279(1361,4.9 \pm 0.8)$ \\
\hline 0427 & Synoptic & $-36.3 \leq T \leq-16.5$ & 17464 & $493(155)$ & 60 & $75(351,4.7 \pm 0.9)$ \\
\hline Total & & & 122871 & $2678(827)$ & 348 & $761(3770,5.0 \pm 1.0)$ \\
\hline
\end{tabular}

the actual morphological characteristics of an ice crystal, but rather are the projected maximum dimension $\left(D^{\prime}\right)$, projected length $\left(L^{\prime}\right)$, and projected width $\left(W^{\prime}\right)$, respectively. In general, the projected dimensions are shorter than the actual di- mensions, which causes errors in determining aspect ratios depending on particle orientations.

Figure 2 shows example CPI images of a bullet rosette, columns, and plates, together with an illustration of how their dimensions were measured using the IC-Ruler. The $D^{\prime}$ 
and $W^{\prime}$ of each individual bullet of a bullet rosette (Fig. 2a) and of columns (Fig. 2b) were measured. When a column is oriented horizontally with respect to the imaging plane (the lower three images in Fig. 2b), the crystal silhouette becomes rectangular. In these cases, the measured $L^{\prime}$ is the actual length of the crystal $L$, whereas the $W^{\prime}$ can have a difference of up to $15.5 \%$ compared with the actual $W$, assuming a hexagonal geometry due to orientations along the $c$ axis. Of the columns measured during TWP-ICE, SPARTICUS, and ISDAC, 21.8, 25.6, and 30.9\% were horizontally oriented (hereafter HCOL) as shown in Tables 4-6, respectively. For plates, $W^{\prime}$ was hard to measure due to orientations, and only $D^{\prime}$ and $L^{\prime}$ were determined (Fig. 2c).

The boundaries of the ice crystals were identified and the particle dimensions were then determined by applying a scaling factor using the IC-Ruler. The CPIView software supplied by SPEC Inc. automatically determines dimensions of particles based on the gradient of pixel intensity. However, most particle dimensions analyzed in this study could not be determined from CPIView and, thus, the manually determined IC-Ruler dimensions are used. The only dimension that can be determined by both manual measurement using the IC-Ruler and the automatic CPIView software is $D^{\prime}$ of columns and plates. To assess uncertainty, the manually measured $D^{\prime}$ of the ice crystals was compared against the automatic measurement from CPIView. Figure 3 compares these measures of $D^{\prime}$ for 11383 columns and 3936 plates using data from all three campaigns. The $D^{\prime}$ measured by IC-Ruler and CPIView have a correlation coefficient of $r=0.997$, and the ratio between $D^{\prime}$ measured by IC-Ruler to that by CPIView averages $1.0041 \pm 0.072$. Few large differences are shown in Fig. 3, and when such differences occur, they were due to erroneous edge detection with CPIView, which can happen when there are bright parts within an ice crystal, such as that caused by the hollows of an ice crystal. Therefore, any impact of errors due to the manual nature of the analysis is negligible.

\section{Results}

\subsection{Ice crystal habit and temperature}

Figure 4 shows the numbers and relative fractions of the measured pristine crystals as a function of temperature. The top row shows the number of crystals and the fractions shown in the bottom row are normalized by the total number of all three habits within each temperature bin in which more than 14 data points are available. It should be noted that the distribution of samples as a function of temperature is partly a function of the altitude where clouds were located and partly a function of the altitudes chosen for sampling during the campaign. Thus, only the relative fraction of different habits within a given temperature range was examined.
Ice crystals were measured during TWP-ICE in the tropics, SPARTICUS at mid-latitudes, and ISDAC in the Arctic fall in the approximate temperature ranges of $-80<T<$ $-35^{\circ} \mathrm{C},-65<T<-15^{\circ} \mathrm{C}$, and $-40<T<-15^{\circ} \mathrm{C}$, respectively. Thus, ice crystals were sampled at lower temperatures during TWP-ICE compared with SPARTICUS and ISDAC sampling at progressively higher $T$. Larger numbers of ice crystals were analyzed during SPARTICUS (i.e., 13919 crystals) compared to TWP-ICE (4799 crystals) and ISDAC (3787 crystals) because a greater number of relevant flight hours were available from that campaign.

The relative fraction of each pristine crystal habit varies for the different campaigns. For example, $40.9 \%$ (43.5; $15.6 \%$ ) of analyzed pristine crystals were columns (plates; bullet rosettes) during TWP-ICE, whereas it was $48.3 \%$ $(10.8 ; 40.9 \%)$ and $70.7 \%(9.2 ; 20.1 \%)$ for SPARTICUS and ISDAC, respectively. During TWP-ICE, the maximum fraction of plates was found at $T \sim-65^{\circ} \mathrm{C}$, whereas that of columns and bullet rosettes was at $T \sim-50^{\circ} \mathrm{C}$. During SPARTICUS, columns and bullet rosettes were the dominant habits of pristine crystals and the fraction of bullet rosettes $(40.9 \%)$ was much higher than during the other campaigns (i.e., 15.6 and $20.1 \%$ for TWP-ICE and ISDAC, respectively). The relatively higher percentage of bullet rosettes agrees with results from Lawson et al. (2006), who classified CPI images in mid-latitude cirrus clouds. They classified CPI images collected from 22 missions over 4 years and found that the mass concentration of rosette shapes constituted approximately $40 \%$ at $-50^{\circ} \mathrm{C}, 55 \%$ at $-40^{\circ} \mathrm{C}$, and $80 \%$ at $-30^{\circ} \mathrm{C}$. The maximum fraction of both columns and bullet rosettes was at $T \sim-55^{\circ} \mathrm{C}$, while that of plates was at $T \sim-40^{\circ} \mathrm{C}$, as shown in Fig. 4. It is an interesting feature that most of analyzed crystals at $T \sim-5^{\circ} \mathrm{C}$ were columns during SPARTICUS and ISDAC, as explained later. Compared with the other two campaigns, ice crystals sampled during ISDAC occurred in a narrower temperature range $\left(-40<T<-20^{\circ} \mathrm{C}\right)$. The numbers of columns were much higher than those of plates and bullet rosettes during ISDAC.

For a given temperature range (bottom row of Fig. 4), the fractional contributions of bullet rosettes have a maximum near $T \sim-45^{\circ} \mathrm{C}$ for all three geographic regimes. This is in contrast with the results from Lawson et al. (2006), who found that the mass percentage of "rosette shapes" increased between -50 and $-30^{\circ} \mathrm{C}$. This may be due to their inclusion of rosettes with riming and sideplanes, whereas the current study considered only pristine bullet rosettes. Plate crystals show exactly the opposite pattern, with a minimum fraction at $T \sim-45^{\circ} \mathrm{C}$, whereas columns were ubiquitous for all $T$. These fractional distributions in Fig. 4 are somewhat different from the habit diagrams presented by Bailey and Hallett $(2004,2009)$. For example, they showed that plate-like crystals exist at $-40<T<-20^{\circ} \mathrm{C}$ (plate-like regime), whereas columnar crystals are dominant at $-70<$ $T<-40^{\circ} \mathrm{C}$ (columnar regime). These two distinct regimes are not clear in Fig. 4, with plates having a higher fraction 
(a)

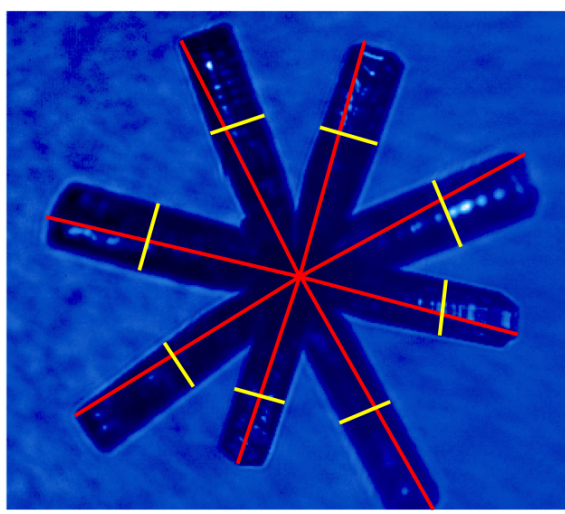

$T=-41.7 \quad D^{\prime}=804.36$

(c)
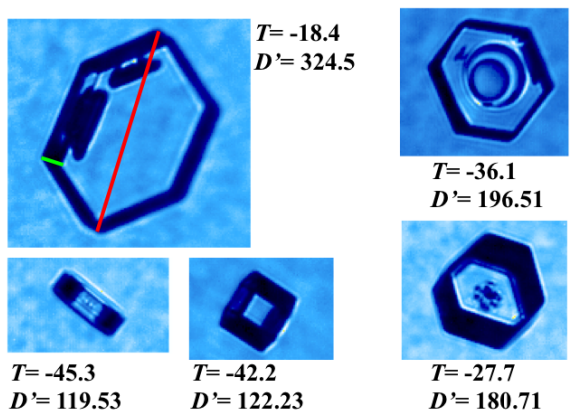

(b)
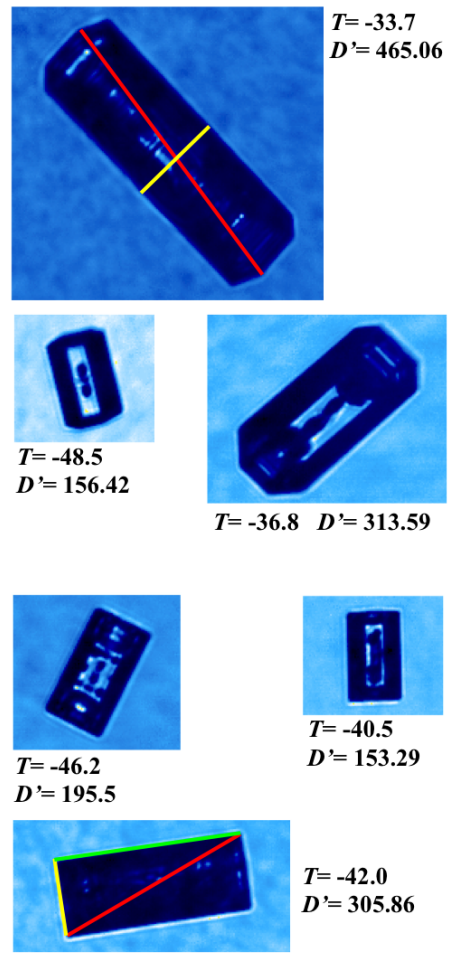

Figure 2. Example CPI images of ice crystals: (a) bullet rosette, (b) columns, and (c) plates taken during SPARTICUS. The projected maximum dimension $\left(D^{\prime}\right.$, red), projected width $\left(W^{\prime}\right.$, yellow), and projected length $\left(L^{\prime}\right.$, green), are indicated in the first crystal in each panel. For each crystal, temperature $\left(T,{ }^{\circ} \mathrm{C}\right)$ and projected maximum dimension $\left(D^{\prime}, \mu \mathrm{m}\right)$ are listed. For columns, the upper three images are columns with orientations, whereas the lower three are horizontally oriented with respect to the imaging plane.

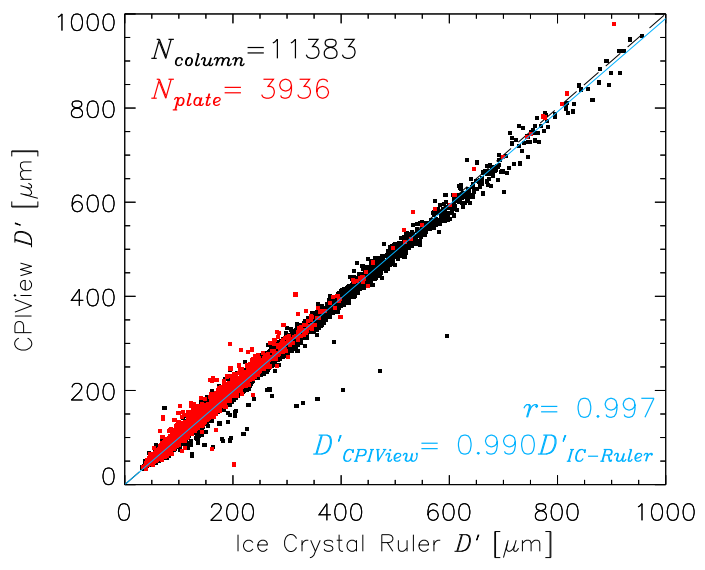

Figure 3. A comparison between the projected maximum dimension $\left(D^{\prime}\right)$ of columns (black) and plates (red) measured using the Ice Crystal Ruler (IC-Ruler) and those obtained from CPIView. Correlation coefficient $(r)$ and slope of best fit line of CPIView $D^{\prime}$ against $D^{\prime}$ from IC-Ruler embedded in the panel. The black dashed line is a $1: 1$ line.

than columnar crystals at $T<\sim-55^{\circ} \mathrm{C}$ during TWP-ICE. Of course, the analysis is complicated by the fact that crystals are observed at locations where they did not necessarily form, and have grown or sublimated on paths taking them through different regimes.

During TWP-ICE, Um and McFarquhar (2009) showed much higher occurrence of plates and their aggregates on 2 February compared with the other 2 days, 27 and 29 January, when aged cirrus were sampled. The analyzed plates at $T<\sim-55^{\circ} \mathrm{C}$ were sampled within convective anvils on 2 , 6, 10, and 12 February during TWP-ICE (see Table 4). They were most likely generated at higher temperatures under different environmental conditions and subsequently raised to lower temperatures by convection. Thus, transport (e.g., convection, advection, and sedimentation) as well as environmental conditions govern the relation between temperature and crystal habit. Because of this, Bailey and Hallett (2004) indicated that in situ aircraft observations of ice crystals could lead to a skewed view of correlation between temperature and habit. However, knowledge of correlations between microphysical properties (e.g., habit and size) of ice crystals and environmental conditions at a sample location is just as important as with properties at the place of crystal origin for verification of numerical models and retrieval algorithms. 


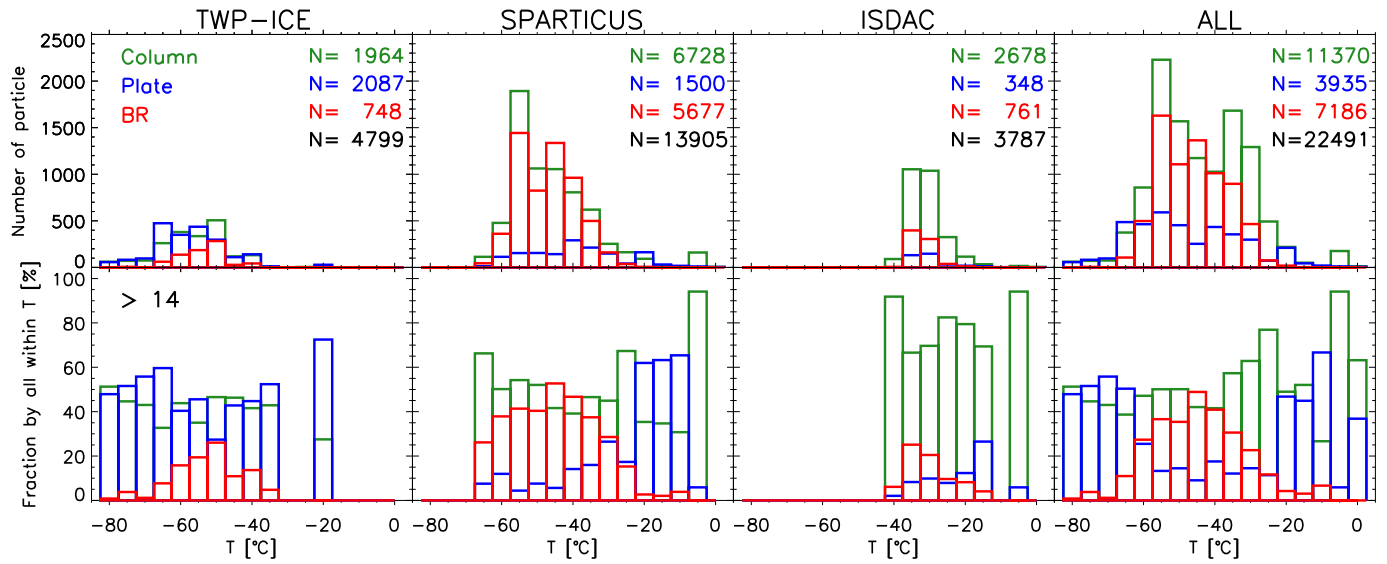

Figure 4. Numbers of particles measured during TWP-ICE, SPARTICUS, ISDAC, and all three campaigns (ALL) as a function of temperature in the top row. The corresponding fraction $(\%)$ normalized by total numbers of all three habits within temperature bins in which more than 14 samples are available is shown in the bottom row. Different colors indicate different crystal habits, and the total numbers of each habit and of all three habits are embedded.

\subsection{Dependence of dimensions of crystals on temperature}

Temperature is a critical factor governing the microphysical properties (e.g., size, aspect ratio, and habit) of ice crystals. Figure 5 shows the measured dimensions of columns using the IC-Ruler as a function of $T$ for each field campaign separately and for all three campaigns combined. To quantify the dependence of crystal dimensions on $T$, the mean and standard deviation of crystal dimensions were calculated for $10^{\circ} \mathrm{C}$ temperature intervals from $0{ }^{\circ} \mathrm{C}$, with the last interval representing the range -85 to $-70^{\circ} \mathrm{C}$, and are shown with black circles and lines in each panel. For statistical significance, the mean and standard deviation are only shown for temperature ranges for which more than 14 crystals were analyzed.

The top two rows show the projected maximum dimension $D^{\prime}$ and width $W^{\prime}$ of all columns. The columns are divided into two categories: oriented columns (OCOL) and horizontal columns (HCOL), whose dimensions are shown in the lower panels. The HCOLs are horizontally oriented columns as shown in Fig. 2b (bottom three columns), whereas other columns are classified as OCOL as shown in Fig. 2b (top three columns). For HCOLs, an additional dimension, the projected length $L^{\prime}$, was also measured and is shown in Fig. 5 (bottom row), whereas $L^{\prime}$ cannot be unambiguously determined for the OCOLs.

All measured dimensions of columns show a strong dependence on temperature as shown by the correlation coefficients $r$ listed in Fig. 5. Previous studies showed that the rate of propagation of steps at the surface of ice crystals (i.e., Hallett, 1961) and the linear growth rate of the basal and prism faces (i.e., Lamb and Hobbs, 1971), in general, increased with $T$, and, thus, an increase in crystal dimensions as $T$ increases is natural. Furthermore, there may be more time for growth if the crystals are falling from aloft. The mean dimensions all increase with temperature except for the $W^{\prime}$ measured during SPARTICUS and $D^{\prime}$ and $W^{\prime}$ for ISDAC measured at $-10<T<0^{\circ} \mathrm{C}$. This corresponds to 167 and 22 columns at $-10<T<0^{\circ} \mathrm{C}$ for SPARTICUS and ISDAC, respectively. The measured columns in this temperature range have large $D^{\prime}$ but small $W^{\prime}$ during SPARTICUS, whereas they have both small $D^{\prime}$ and $W^{\prime}$ during ISDAC. They were measured on 16 April 2010 during SPARTICUS (flights 0416A and 0416B) and 4 April 2008 during ISDAC (see Tables 5 and 6). Figure 6 shows examples of ice crystals imaged in this $T$ range during SPARTICUS and ISDAC, including both the columns and other non-pristine crystals measured at similar times. Both cases were mixed-phase clouds with many small spherical water droplets evident in Fig. 6. Large crystals observed were columns, sheaths, needles, and their aggregates. There are two critical points between -10 and $0{ }^{\circ} \mathrm{C}$ at which major habit changes occur: from plate-like to needle and long column at $T \sim-3.0^{\circ} \mathrm{C}$ and to plate-like at $T \sim-8.0^{\circ} \mathrm{C}$ (e.g., aufm Kampe et al., 1951; Hallett and Mason, 1958; Hallet, 1965; Ono, 1969, 1970). The columns shown in Fig. 6 during SPARTICUS were sampled at lower temperatures $(-4.8 \pm 1.3)$ than those during ISDAC $(-2.5 \pm 0.1)$. Thus, the long columns measured at $-8.0<T<-2.4^{\circ} \mathrm{C}$ during SPARTICUS were in the growth regime of needles and long columns, whereas those imaged during ISDAC were at transition temperatures from plates to columns and, as a result, have larger AR. In fact, even a plate is shown in Fig. 6 b.

Figure 7 shows the dependence of the projected maximum dimension $D^{\prime}$ and length $L^{\prime}$ of plates on $T$. In this study, plates were divided into two categories: thick and thin plates using a threshold $L^{\prime} / D^{\prime}$ of 0.41 . Although this selected threshold is purely empirical based only on the data used in this study and there might be influences of particle orienta- 


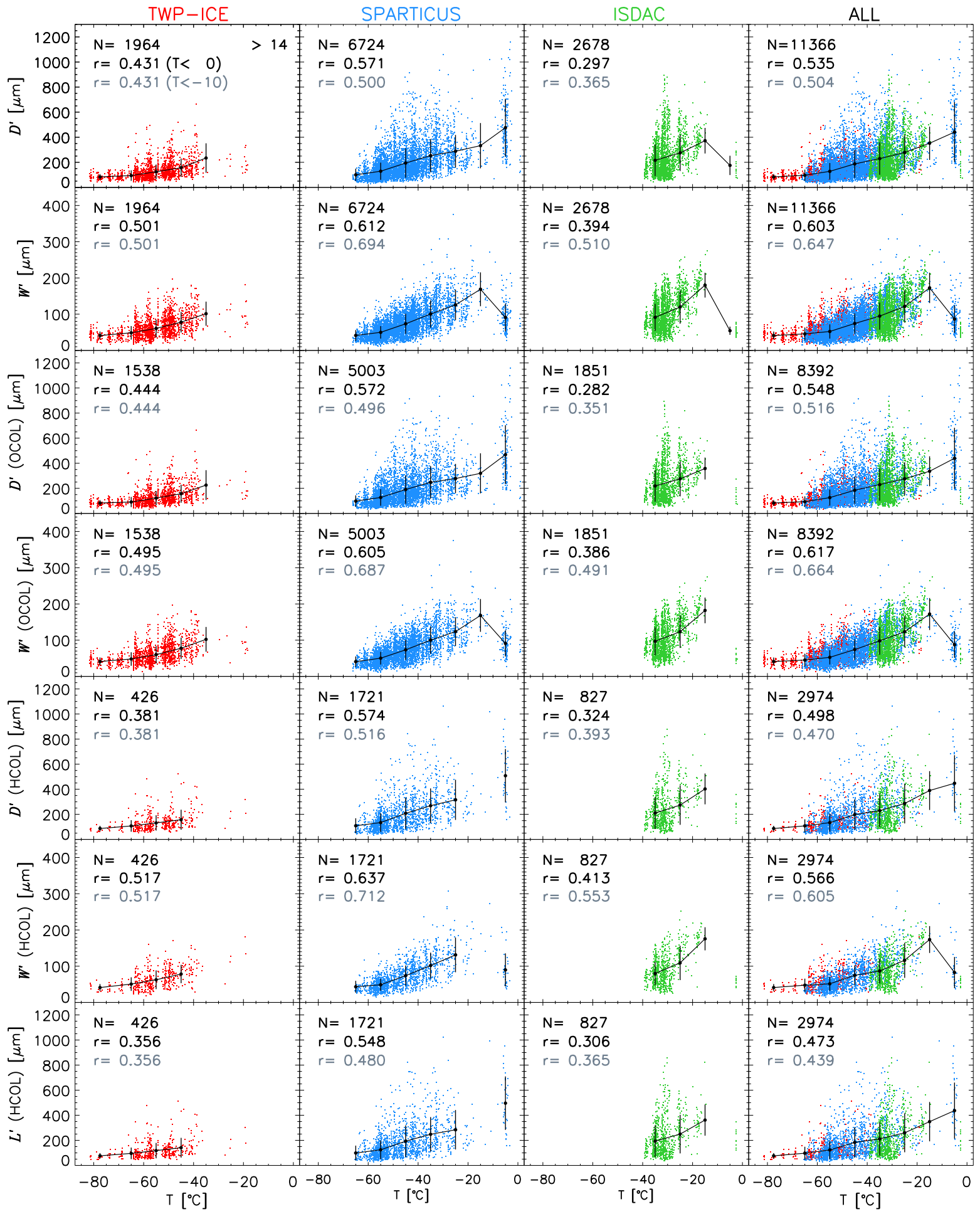

Figure 5. Measured $D^{\prime}, W^{\prime}$, and $L^{\prime}$ of columns as a function of temperature. From left, data from TWP-ICE, SPARTICUS, ISDAC, and all three field campaigns combined (ALL) are shown in each column. HCOL and OCOL indicate columns with horizontal orientation and columns with other orientations, respectively. The number of pristine crystals analyzed is embedded in each panel. The mean and standard deviation are indicated with black circles and vertical bars in each panel calculated over each $10^{\circ} \mathrm{C}$ temperature interval from $0{ }^{\circ} \mathrm{C}$, except for $-85<T<-70^{\circ} \mathrm{C}$. Correlation coefficients $(r)$ for $-85<T<0{ }^{\circ} \mathrm{C}$ (black) and for $-85<T<-10^{\circ} \mathrm{C}$ (gray) are embedded in each panel. 


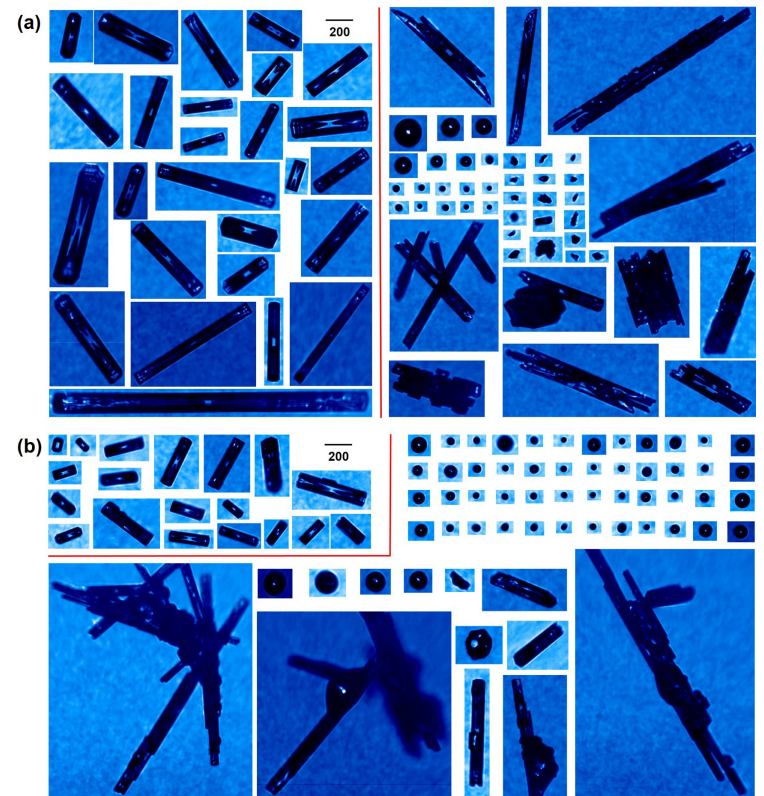

Figure 6. Examples of cloud particles imaged by CPI in mixedphase clouds (a) between 17:39:45-17:50:43 and 21:09:39_ 21:11:25 UTC on 16 April 2010 (SPARTICUS) at $-8.0<T<$ $-2.4^{\circ} \mathrm{C}$ and (b) between 19:59:30 and 20:00:16 UTC on 4 April 2008 (ISDAC) at $-2.6<T<-1.9^{\circ} \mathrm{C}$. In each panel, measured columns (left) and other particles (right) are divided with a red line. A $200 \mu \mathrm{m}$ scale bar is embedded in each panel.

tion, it successfully separates thick and thin plates with better correlation coefficients. Thick plates include solid thick plates $(\mathrm{C} 1 \mathrm{~g})$ and thick plates of skeleton form $(\mathrm{C} 1 \mathrm{~h})$, whereas thin plates are hexagonal plates (P1a) according to the identification codes of Magono and Lee (1966). Plates show an increase in dimension as $T$ increases for all campaigns. The variations in $L^{\prime}$ are much smaller compared to those in $D^{\prime}$, and less correlation between $T$ and $L^{\prime}$ is shown compared to that between $T$ and $D^{\prime}$.

The dimensions (i.e., $D^{\prime}$ and $W^{\prime}$ ) of bullets also increase with $T$ as shown in Fig. 8. The third and fourth rows of Fig. 8 show the relationship between temperature and the dimensions of the bullet rosettes, where the dimension of a bullet rosette is the average of the dimensions of the branches. The dimensions of bullet rosettes also show a dependence on $T$. The bottom row of Fig. 8 shows that there is no distinct dependence on the number of branches of the bullet rosette with $T$. The mean number of branches during the three campaigns was 5.5, with more branches measured during TWPICE (6.3) compared to SPARTICUS (5.5) and ISDAC (5.0).

\section{3 $L-W$ relationships and aspect ratios of ice crystals}

There have been few studies that investigated $L-W$ relationships or ARs of ice crystals over the wide range of temperatures. Therefore, the large data set created here is used to stratify $L-W$ relationships according to $T$ and geophysical location. There have been several definitions used to define an aspect ratio (AR) of ice crystals (e.g., Korolev and Isaac, 2003). In this study, the AR of an ice crystal is defined as the ratio between the dimension along the $c$ axis and the dimension along the $a$ axis of the crystal. The AR of a column is thus defined as $D^{\prime} / W^{\prime}$ or $L^{\prime} / W^{\prime}$ for HCOLs only, as $L^{\prime} / D^{\prime}$ for plates, and as $D^{\prime} / W^{\prime}$ for individual bullets. Thus, columnar crystals (i.e., columns and bullets) have AR $>1.0$, whereas plates have $\mathrm{AR}<1.0$.

Figures 9-11 show $L-W$ relationships and ARs of columns, plates, and bullet rosettes, and corresponding best fits to the plotted variables when more than 39 samples were available. To determine the influence of $T$, measurements were sorted according to five ranges: $-10<T<$ $0{ }^{\circ} \mathrm{C},-30<T<-10^{\circ} \mathrm{C},-40<T<-30{ }^{\circ} \mathrm{C},-52<T<$ $-40^{\circ} \mathrm{C}$, and $-85<T<-52^{\circ} \mathrm{C}$. These ranges were selected to maintain similar numbers of crystals in each sample. Sensitivity studies showed derived relationships were not sensitive to the exact selection of temperature ranges.

The top row in Fig. 9 shows the $D^{\prime}-W^{\prime}$ relationship for all columns. The solid colored best fit lines show larger $W^{\prime}$ as $T$ increases for a given $D^{\prime}$ regardless of campaign, except for $-10<T<0{ }^{\circ} \mathrm{C}$, where narrower columns and needles were frequent, as shown in Figs. 5 and 6. This trend is also shown in $D^{\prime}-W^{\prime}$ relationships of OCOLs (second row) and HCOLs (third row). The $L^{\prime}-W^{\prime}$ relationship of HCOLs (bottom row) also shows the same trend. Lamb and Hobbs (1971) showed that the linear growth rate of the basal and prism faces of hexagonal crystals decreased as $T$ decreased below $T \sim-13^{\circ} \mathrm{C}$. Thus, the larger dimensions (i.e., $W^{\prime}$ ) of the minor axis (i.e., $a$ axis) for a given dimension (i.e., $D^{\prime}$ or $L^{\prime}$ ) of the major axis (i.e., $c$ axis) as $T$ increased is consistent with the previous laboratory measurements. However, Lamb and Hobbs (1971) measured the linear growth rates only for $T>-18^{\circ} \mathrm{C}$, which was controlled by molecular events on the surfaces of the crystal. Thus, further experiments measuring crystal growth by the rate of supply of water molecules from the vapor phase and by the rate at which latent heat of deposition removed are required at colder temperatures.

This same dependence of the $D^{\prime}-L^{\prime}$ relationship on $T$ is not seen for plates in Fig. 10. Both thick and thin plates do not show any systematic dependence on how $L^{\prime}$ varies with $T$ for a given value of $D^{\prime}$. This might occur due to the relatively small number of samples compared with columns and bullets, or due to the smaller variations in $L^{\prime}$ of plates.

Figure 11 shows the $D^{\prime}-W^{\prime}$ relationship of bullets and bullet rosettes. As for columns, there are larger $W^{\prime}$ for higher temperatures for a given $D^{\prime}$, regardless of the campaign. Furthermore, ARs of columns and bullets increase with the minor (i.e., $W^{\prime}$ ) and major (i.e., $L^{\prime}$ or $D^{\prime}$ ) axes, albeit at a reduced rate for larger $W^{\prime}, L^{\prime}$, or $D^{\prime}$. The dependence of the $D^{\prime}-W^{\prime}$ relationship for bullets on the number of branches is also shown in Fig. 11, with the $W^{\prime}$ of bullets decreasing with the number of branches for a given $D^{\prime}$. 


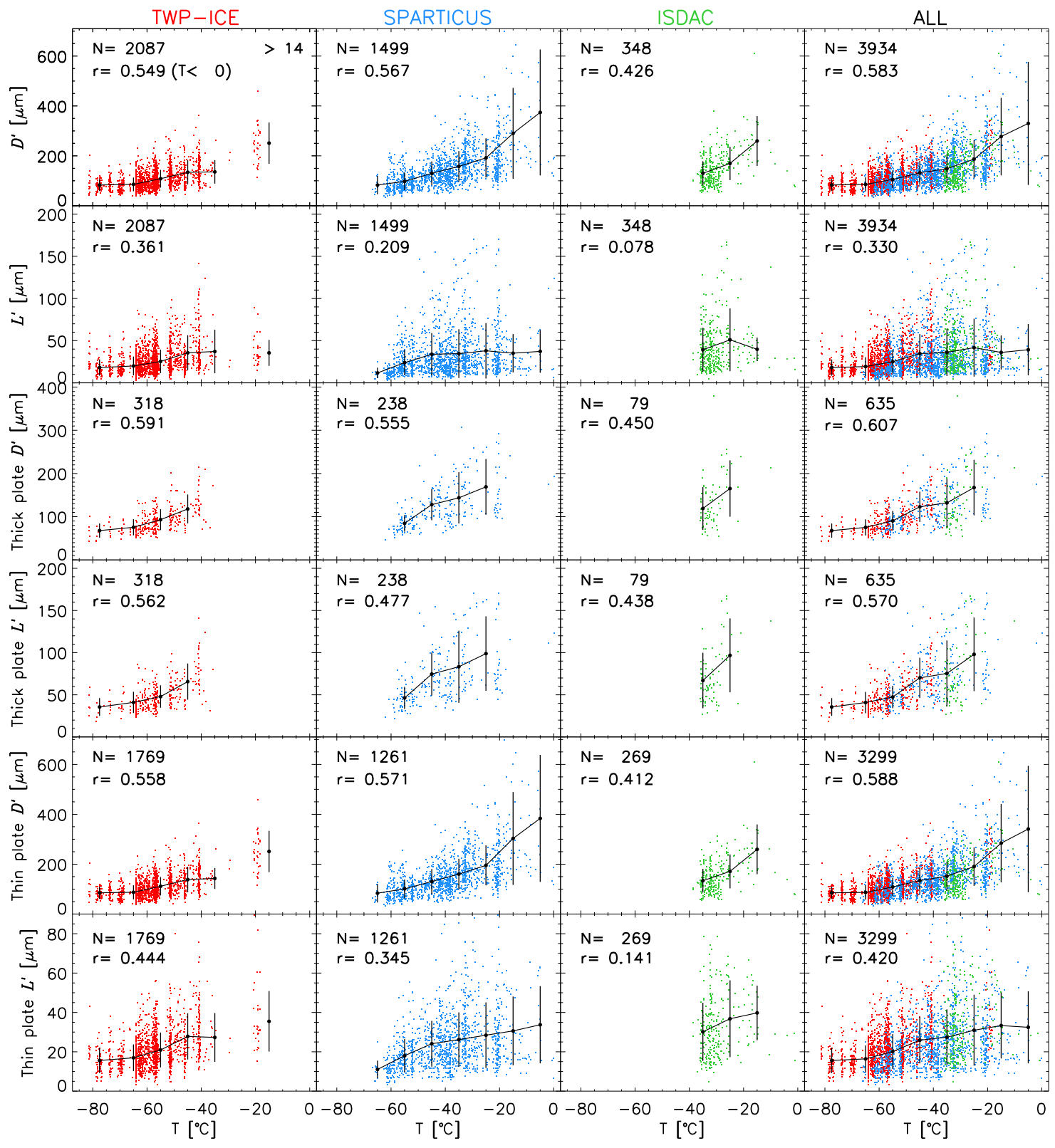

Figure 7. Measured $D^{\prime}$ and $L^{\prime}$ of all plates (top two rows), thick plates (middle two rows), and thin plates (bottom two rows) as a function of temperature. Correlation coefficient $(r)$ for $-85<T<0{ }^{\circ} \mathrm{C}$ is embedded in each panel. Colors and temperature ranges used are the same as in Fig. 5.

Figure 12 shows that the mean AR of columns for a given $T$ has a weak dependence on $T$, but that there can be a wide spread of ARs for a given $T$. Overall, the ARs of columns show broad maxima at $-55<T<-45^{\circ} \mathrm{C}$ and tend to decrease slowly with both an increase and decrease in temperature. The largest AR of a column was 15.77 sampled at $T=-3.7^{\circ} \mathrm{C}$ during SPARTICUS. Columns at $-10<$ $T<0^{\circ} \mathrm{C}$ during SPARTICUS and ISDAC show sharp peaks due to the long nature of the columns found in the needle growth regime previously discussed. Hallett (1965) showed two maxima in the growth rate of ice crystals at $T=-15$ and $-5^{\circ} \mathrm{C}$ based on diffusion cloud chamber measurements. Ono (1970) showed that the ratio of the dimension of the $c$ axis to that of the $a$ axis had a maximum at $T \sim-5^{\circ} \mathrm{C}$ for columnar crystals, whereas the ratio of the dimension of the $a$ axis to that of the $c$ axis (i.e., 1 / AR of plate in this study) had a maximum at $T \sim-15^{\circ} \mathrm{C}$ for plane crystals (e.g., plates). These peaks associated with the maximum growth rate of ice crystals at $T \sim-15$ and $-5^{\circ} \mathrm{C}$ are also observed in this study. The maximum AR of columns at $T \sim-5{ }^{\circ} \mathrm{C}$ is clearly shown 


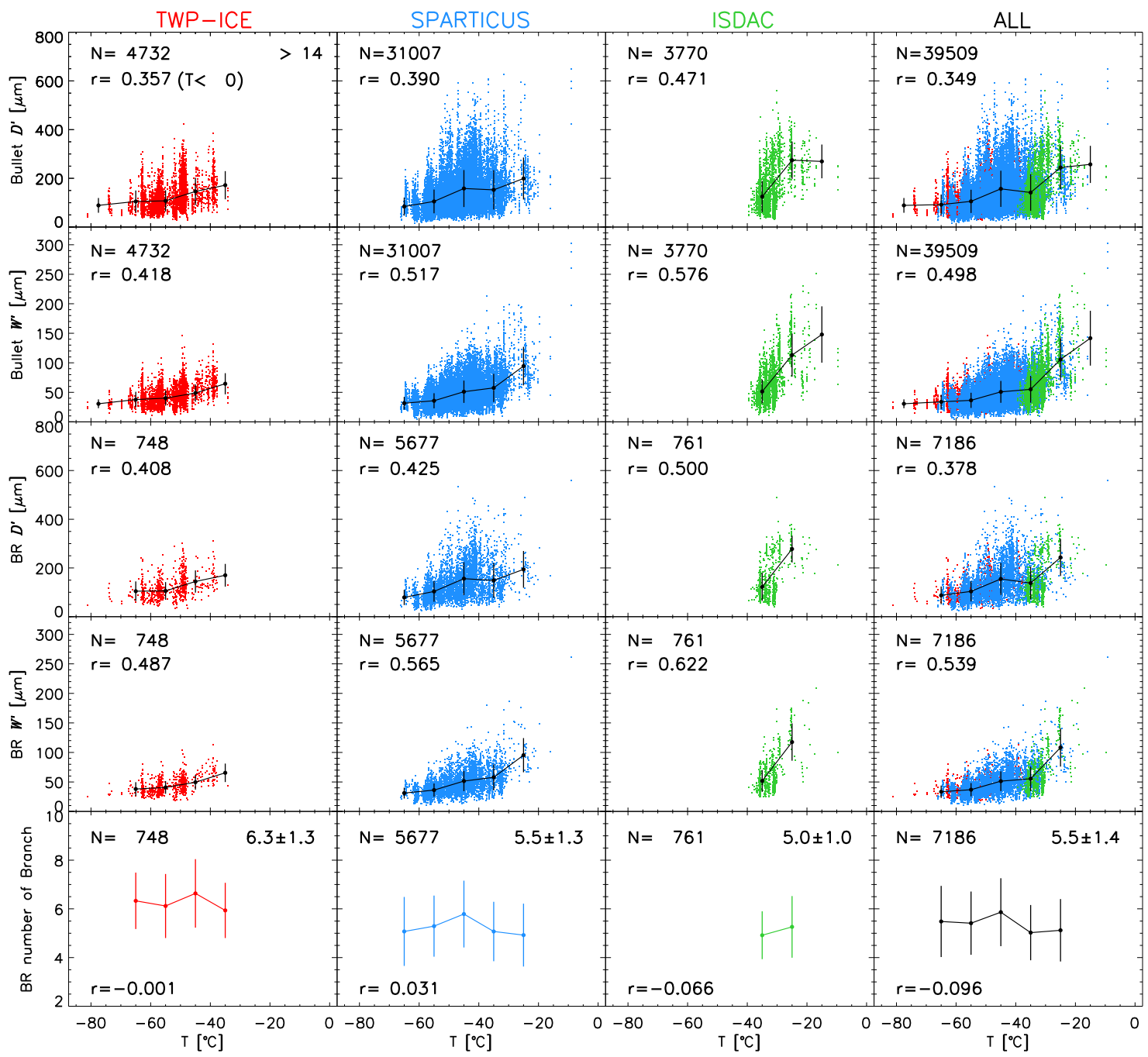

Figure 8. As in Fig. 7 except for bullets (top two rows) and bullet rosettes (BR, third and fourth rows from the top). Here, each dimension for a BR is the average of its component bullets. Mean and standard deviation of the number of bullet rosettes are shown in the bottom row.

in Fig. 12, whereas the minimum AR of plates at $T \sim-15^{\circ} \mathrm{C}$ is shown in Fig. 13. The ARs of thick and thin plates also show a weak dependence on $T$, with a slight decrease at $T>-20^{\circ} \mathrm{C}$.

Figure 14 shows that the ARs of bullets and bullet rosettes tend to decrease with $T$. However, the $r$ were extremely small, suggesting that the dependence of AR on $T$ was very weak. The largest AR of a bullet was 11.85, sampled at $T=$ $-53.2^{\circ} \mathrm{C}$ during SPARTICUS. The bottom row of Fig. 14 shows ARs of bullets as a function of temperature and the number of branches. Bullets in a bullet rosette with a larger number of branches have larger AR, and it decreases as the number of branches decreases, regardless of the temperature or campaigns.

In this study, several $L-W$ relationships and hence different ARs were derived, depending on the dimensions used to define the ARs and the methodology used to measure the di- mensions. The $L^{\prime}-W^{\prime}$ relationship for HCOLs is the closest to that of actual columns and, thus, is used as a reference value. Figure 15 illustrates the differences between $W^{\prime}$ of HCOLs derived from $L^{\prime}-W^{\prime}$ relationships for HCOLs and four different $W^{\prime}$ s derived from $D^{\prime}-W^{\prime}$ relationships (i.e., all columns, CPIView, OCOLs, and HCOLs, which are denoted as $y$ in Fig. 15) for the same $D^{\prime}$ corresponding to the $L^{\prime}$ of HCOLs. Here, CPIView represents the direct measurement of $D^{\prime}$ and $W^{\prime}$ from in situ data, and it causes a difference of up to $21 \%$ in $W^{\prime}$ for a given $D^{\prime}$ (or $L^{\prime}$ ) and hence the same difference in AR. Other relationships can cause a difference of up to $14 \%$ in $W^{\prime}$ and hence AR, which depends on $D^{\prime}$ or $L^{\prime}$. These differences are caused by the different definitions of dimensions and ARs, and due to orientations of ice crystals. Thus, caution should be taken when comparing crystal dimensions and $L-W$ relationships derived from different 
Table 7. A comparison between dimensions $(\mu \mathrm{m})$, aspect ratios, and occurrence frequency $(\%)$ of columns, plates, bullets, and bullet rosettes (BR) at $-67<T<-35^{\circ} \mathrm{C}$ (TWP-ICE vs. SPARTICUS) and at $-40<T<-15^{\circ} \mathrm{C}$ (SPARTICUS vs. ISDAC). Mean and standard deviation of dimensions and aspect ratios are shown. The numbers in parentheses indicate the number of samples for each category. The occurrence percentage is normalized by the total number of columns, plates, and bullet rosettes, and the fraction in all clouds (fraction in anvil clouds, fraction in non-anvil clouds) is shown.

\begin{tabular}{|c|c|c|c|c|}
\hline & \multicolumn{2}{|c|}{$-67<T<-35^{\circ} \mathrm{C}$} & \multicolumn{2}{|c|}{$-40<T<-15^{\circ} \mathrm{C}$} \\
\hline & TWP-ICE & SPARTICUS & SPARTICUS & ISDAC \\
\hline Column $D^{\prime}$ & $129.6 \pm 68.8(1737)$ & $162.1 \pm 101.4(5763)$ & $263.8 \pm 133.8(1415)$ & $237.2 \pm 135.2(2652)$ \\
\hline Column $W^{\prime}$ & $63.7 \pm 27.8$ & $62.7 \pm 27.9$ & $108.2 \pm 41.5$ & $101.8 \pm 44.1$ \\
\hline Column $D^{\prime} / W^{\prime}$ & $2.12 \pm 0.87$ & $2.59 \pm 0.97$ & $2.45 \pm 0.80$ & $2.30 \pm 0.72$ \\
\hline OCOL $D^{\prime}$ & $127.2 \pm 67.7(1354)$ & $159.7 \pm 99.0(4289)$ & $257.7 \pm 129.3(1041)$ & $239.4 \pm 132.7(1835)$ \\
\hline OCOL $W^{\prime}$ & $63.1 \pm 28.0$ & $62.9 \pm 27.8$ & $107.6 \pm 41.5$ & $107.0 \pm 44.1$ \\
\hline OCOL $D^{\prime} / W^{\prime}$ & $2.10 \pm 0.86$ & $2.54 \pm 0.92$ & $2.41 \pm 0.77$ & $2.19 \pm 0.63$ \\
\hline HCOL $D^{\prime}$ & $138.0 \pm 71.9(383)$ & $169.0 \pm 107.9(1474)$ & $281.0 \pm 144.3(374)$ & $232.2 \pm 140.6(817)$ \\
\hline $\mathrm{HCOL} L^{\prime}$ & $124.3 \pm 71.2$ & $156.5 \pm 106.3$ & $257.4 \pm 142.7$ & $212.4 \pm 138.0$ \\
\hline HCOL $W^{\prime}$ & $65.8 \pm 26.9$ & $62.0 \pm 28.5$ & $109.8 \pm 41.6$ & $90.1 \pm 41.7$ \\
\hline HCOL $D^{\prime} / W^{\prime}$ & $2.19 \pm 0.91$ & $2.74 \pm 1.11$ & $2.57 \pm 0.87$ & $2.54 \pm 0.84$ \\
\hline $\operatorname{HCOL~} L^{\prime} / W^{\prime}$ & $1.98 \pm 0.94$ & $2.54 \pm 1.15$ & $2.36 \pm 0.92$ & $2.32 \pm 0.91$ \\
\hline Plate $D^{\prime}$ & $104.9 \pm 39.5(1820)$ & $117.0 \pm 46.6(954)$ & $175.1 \pm 78.0(757)$ & $147.6 \pm 65.8(339)$ \\
\hline Plate $L^{\prime}$ & $25.2 \pm 15.6$ & $28.3 \pm 21.9$ & $35.9 \pm 29.9$ & $42.6 \pm 29.5$ \\
\hline Plate $L^{\prime} / D^{\prime}$ & $0.25 \pm 0.14$ & $0.25 \pm 0.17$ & $0.22 \pm 0.16$ & $0.30 \pm 0.16$ \\
\hline Thick plate $D^{\prime}$ & $94.2 \pm 30.2(286)$ & $109.8 \pm 38.3(170)$ & $152.4 \pm 61.2(107)$ & $132.1 \pm 58.0(78)$ \\
\hline Thick plate $L^{\prime}$ & $50.2 \pm 18.3$ & $62.5 \pm 26.3$ & $87.5 \pm 42.5$ & $75.4 \pm 38.5$ \\
\hline Thick plate $L^{\prime} / D^{\prime}$ & $0.53 \pm 0.07$ & $0.56 \pm 0.08$ & $0.56 \pm 0.08$ & $0.56 \pm 0.07$ \\
\hline Thin plate $D^{\prime}$ & $106.8 \pm 40.7(1534)$ & $118.5 \pm 48.1(784)$ & $178.8 \pm 79.8(650)$ & $152.3 \pm 67.4(261)$ \\
\hline Thin plate $L^{\prime}$ & $20.6 \pm 9.5$ & $20.9 \pm 11.2$ & $27.4 \pm 15.3$ & $32.7 \pm 16.5$ \\
\hline Thin plate $L^{\prime} / D^{\prime}$ & $0.20 \pm 0.08$ & $0.18 \pm 0.08$ & $0.17 \pm 0.08$ & $0.22 \pm 0.08$ \\
\hline Bullet $D^{\prime}$ & $123.7 \pm 53.6(4653)$ & $135.1 \pm 71.6(29269)$ & $155.9 \pm 82.1(4788)$ & $144.8 \pm 83.1(3765)$ \\
\hline Bullet $W^{\prime}$ & $43.9 \pm 15.0$ & $45.0 \pm 18.8$ & $60.1 \pm 26.4$ & $59.9 \pm 31.8$ \\
\hline Bullet $D^{\prime} / W^{\prime}$ & $2.90 \pm 1.02$ & $3.07 \pm 1.11$ & $2.66 \pm 0.91$ & $2.47 \pm 0.81$ \\
\hline $\mathrm{BR} D^{\prime}$ & $121.6 \pm 45.7(736)$ & $131.7 \pm 64.2(5309)$ & $152.0 \pm 72.9(947)$ & $142.1 \pm 77.2(760)$ \\
\hline $\mathrm{BR} W^{\prime}$ & $44.4 \pm 13.4$ & $45.1 \pm 17.3$ & $60.6 \pm 24.7$ & $60.3 \pm 30.7$ \\
\hline $\mathrm{BR} D^{\prime} / W^{\prime}$ & $2.74 \pm 0.62$ & $2.89 \pm 0.69$ & $2.51 \pm 0.61$ & $2.35 \pm 0.53$ \\
\hline BR branch & $6.32 \pm 1.34$ & $5.51 \pm 1.34$ & $5.06 \pm 1.23$ & $4.95 \pm 1.02$ \\
\hline Column fraction & $40.5(31.0,56.5)$ & $47.9(43.7,48.7)$ & $45.4(27.66,52.6)$ & $70.7(0.0,70.7)$ \\
\hline Plate fraction & $42.4(56.1,6.0)$ & $7.9(30.6,3.9)$ & $24.3(57.85,10.6)$ & $9.0(0.0,9.0)$ \\
\hline $\mathrm{BR}$ fraction & $17.1(12.9,37.5)$ & $44.2(25.7,47.4)$ & $30.4(14.49,36.8)$ & $20.3(0.0,20.3)$ \\
\hline
\end{tabular}

in situ data sets, which frequently use different variables to describe the relationships.

\subsection{Dependence on geophysical locations and type of cirrus}

Two temperature ranges, $-67<T<-35^{\circ} \mathrm{C}$ and $-40<$ $T<-15^{\circ} \mathrm{C}$, were selected in order to compare how the microphysical properties of the crystals varied with geophysical location (i.e., tropics, mid-latitudes, and the Arctic). Table 7 lists how the microphysical properties vary with geophysical regime for these two $T$ ranges. At $-67<T<-35^{\circ} \mathrm{C}$, the properties of the TWP-ICE and SPARTICUS ice crystals are compared, whereas the SPARTICUS and ISDAC properties are compared at $-40<T<-15^{\circ} \mathrm{C}$. Additionally, all measured dimensions and aspect ratios of ice crystals and the number of branches in bullet rosettes at $-67<T<-15^{\circ} \mathrm{C}$ are summarized in Fig. 16 at $5{ }^{\circ} \mathrm{C}$ intervals. Although the temperature range of $-40<T<-35^{\circ} \mathrm{C}$ overlaps all three campaigns, the number of samples obtained during TWPICE is not sufficient for statistical analysis and comparison with other campaigns. Only 52, 20, and 31 columns, plates, and bullet rosettes were measured at this temperature range during TWP-ICE.

For $-67<T<-35^{\circ} \mathrm{C}$, most crystal dimensions measured during SPARTICUS were larger than those obtained during TWP-ICE except for $W^{\prime}$ (see Table 7), and the differences between projects increase with temperature (see Fig. 16). The ARs of columns and bullet rosettes derived from SPARTICUS are also larger than those from TWP-ICE, whereas ARs of plates are similar for TWP-ICE and SPARTICUS.

For $-40<T<-15^{\circ} \mathrm{C}$, most crystal dimensions and calculated ARs are larger for SPARTICUS than for ISDAC. The 


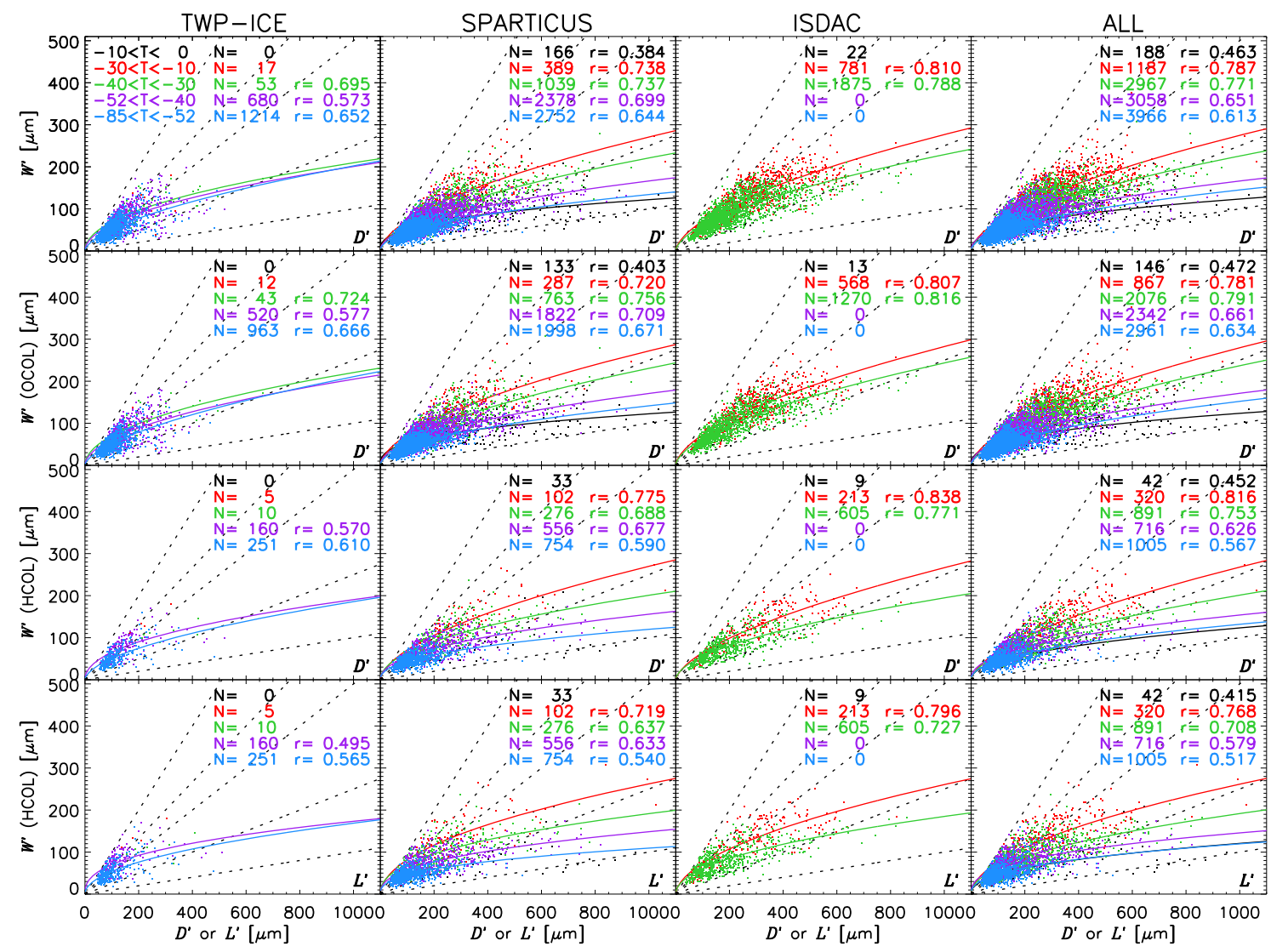

Figure 9. The $D^{\prime}-W^{\prime}$ relationship of all columns (top row), oriented columns (second row, OCOL), and horizontally oriented columns (third row, HCOL) as a function of temperature. Different colors indicate different temperature ranges. Bottom row shows $L^{\prime}-W^{\prime}$ relationships for HCOLs. The number of crystals $(N)$ in each temperature range is embedded within each panel. The best fit, $y=a x^{\mathrm{b}}$, is shown with a solid line and correlation coefficient $r$ is indicated in the legend for each $T$ range. The $x / y=1.0,1.5,2.0,4.0$, and 10.0 lines are indicated with dotted lines.

average number of branches in bullet rosettes from TWP$\operatorname{ICE}(6.32 \pm 1.34)$ is larger than SPARTICUS $(5.51 \pm 1.34)$ at $-67<T<-35^{\circ} \mathrm{C}$, whereas the number for SPARTIUCS $(5.06 \pm 1.23)$ is slightly larger than for ISDAC $(4.95 \pm 1.02)$ at $-40<T<-15^{\circ} \mathrm{C}$. The ARs of bullets increase with the number of branches in bullet rosettes as shown in Figs. 11 and 14 , whereas the ARs (i.e., $D^{\prime} / W^{\prime}$ ) of bullets from SPARTICUS are larger than those from TWP-ICE even though the mean number of branches in bullet rosettes of TWPICE is larger than that of SPARTICUS at $-67<T<-35^{\circ} \mathrm{C}$ (bottom row of Fig. 16). This is caused by the more frequent occurrence of bullet rosettes at colder temperatures within $-67<T<-35^{\circ} \mathrm{C}$ during SPARTICUS, whereas bullet rosettes occurred at warmer temperatures during TWPICE (Fig. 4). The ARs of columnar crystals increase with the dimension of the major axis, whereas dimensions of crystals increase with $T$. Thus, the influence of $T$ on the dimensions and ARs of bullets might be larger than that of the number of branches. At $-40<T<-15^{\circ} \mathrm{C}$, the mean number of branches and ARs of bullet rosettes from SPARTICUS are both larger than those from ISDAC.
To test whether the differences in microphysical properties of ice crystals between campaigns shown in Fig. 16 and Table 7 are statistically significant, the Mann-Whitney $U$ test (Wilcoxon, 1945; Mann and Whitney, 1947) was applied at the 0.05 significance level. The Mann-Whitney $U$ test was applied only to the dimensions and ARs of HCOLs and to the number of branches in bullet rosettes. At $-67<$ $T<-35^{\circ} \mathrm{C}$, all dimensions and $\operatorname{ARs}\left(D^{\prime} / W^{\prime}\right.$ and $\left.L^{\prime} / W^{\prime}\right)$ of HCOLs and the number of branches in bullet rosettes from TWP-ICE and SPARTICUS are statistically distinct for the entire data set and for each $5^{\circ} \mathrm{C}$ interval (Fig. 16), except for the dimensions of HCOLs. The dimensions along the $c$ axis (i.e., $D^{\prime}$ and $L^{\prime}$ ) of HCOLs from TWP-ICE and SPARTICUS are statistically distinct only for $T>-50^{\circ} \mathrm{C}$, whereas $W^{\prime}$ is distinct at colder temperatures $\left(T<-45^{\circ} \mathrm{C}\right)$. At $-40<T<-15^{\circ} \mathrm{C}$, all dimensions $\left(D^{\prime}, L^{\prime}\right.$, and $\left.W^{\prime}\right)$ of HCOLs from SPARTICUS and ISDAC are statistically distinct for the whole data set and for each $5^{\circ} \mathrm{C}$ interval. But, the ARs of HCOLs and the number of branches in bullet rosettes are not statistically distinct sampled over all temperatures and for each $5^{\circ} \mathrm{C}$ interval, except for $L^{\prime} / W^{\prime}$ at 


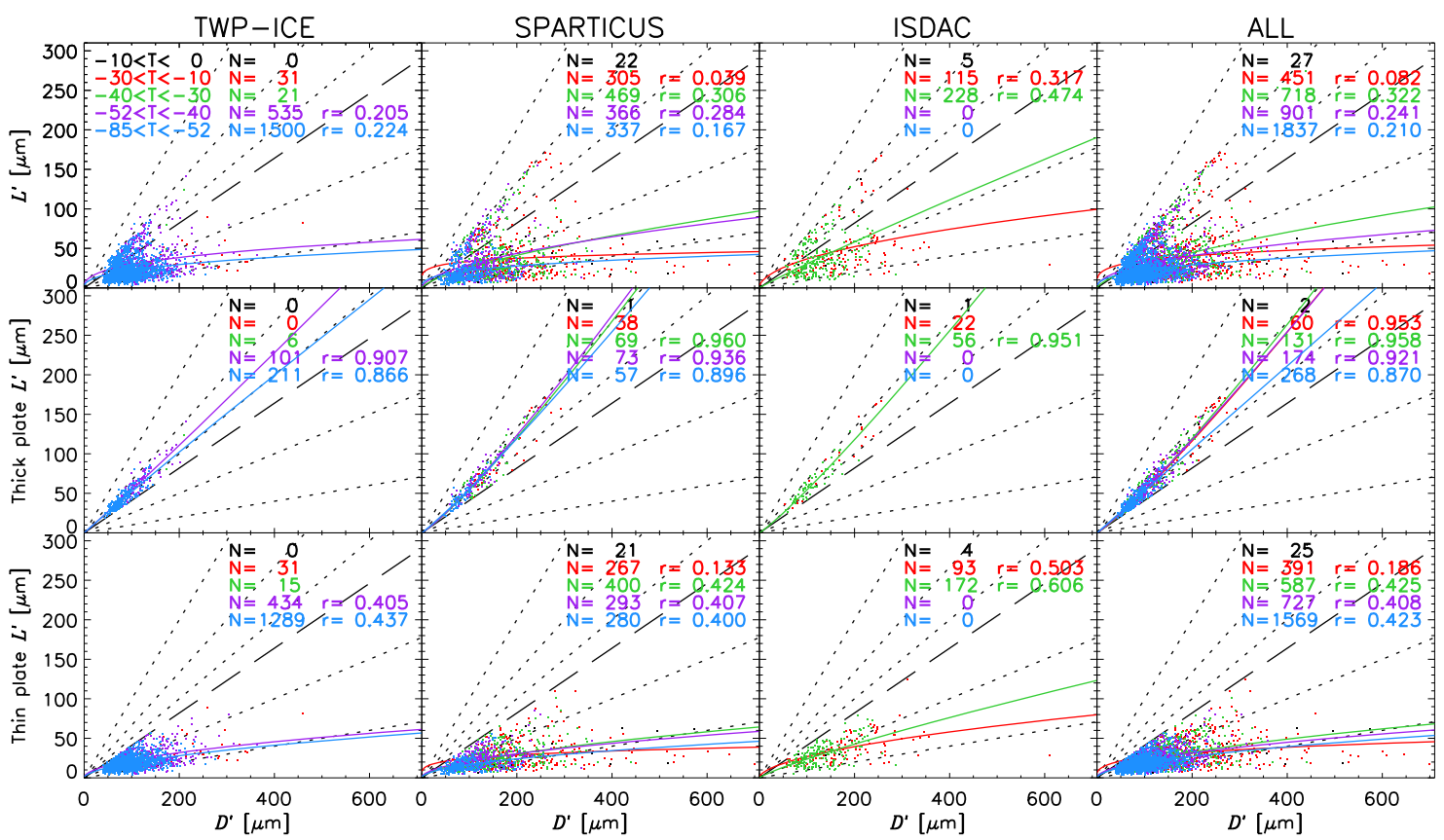

Figure 10. The $D^{\prime}-L^{\prime}$ relationship of all plates (top row), thick plates (second row), and thin plates (third row) as a function of $T$. A black long-dashed line $\left(L^{\prime} / D^{\prime}=0.41\right)$ by which thick and thin plates are categorized is shown in each panel.

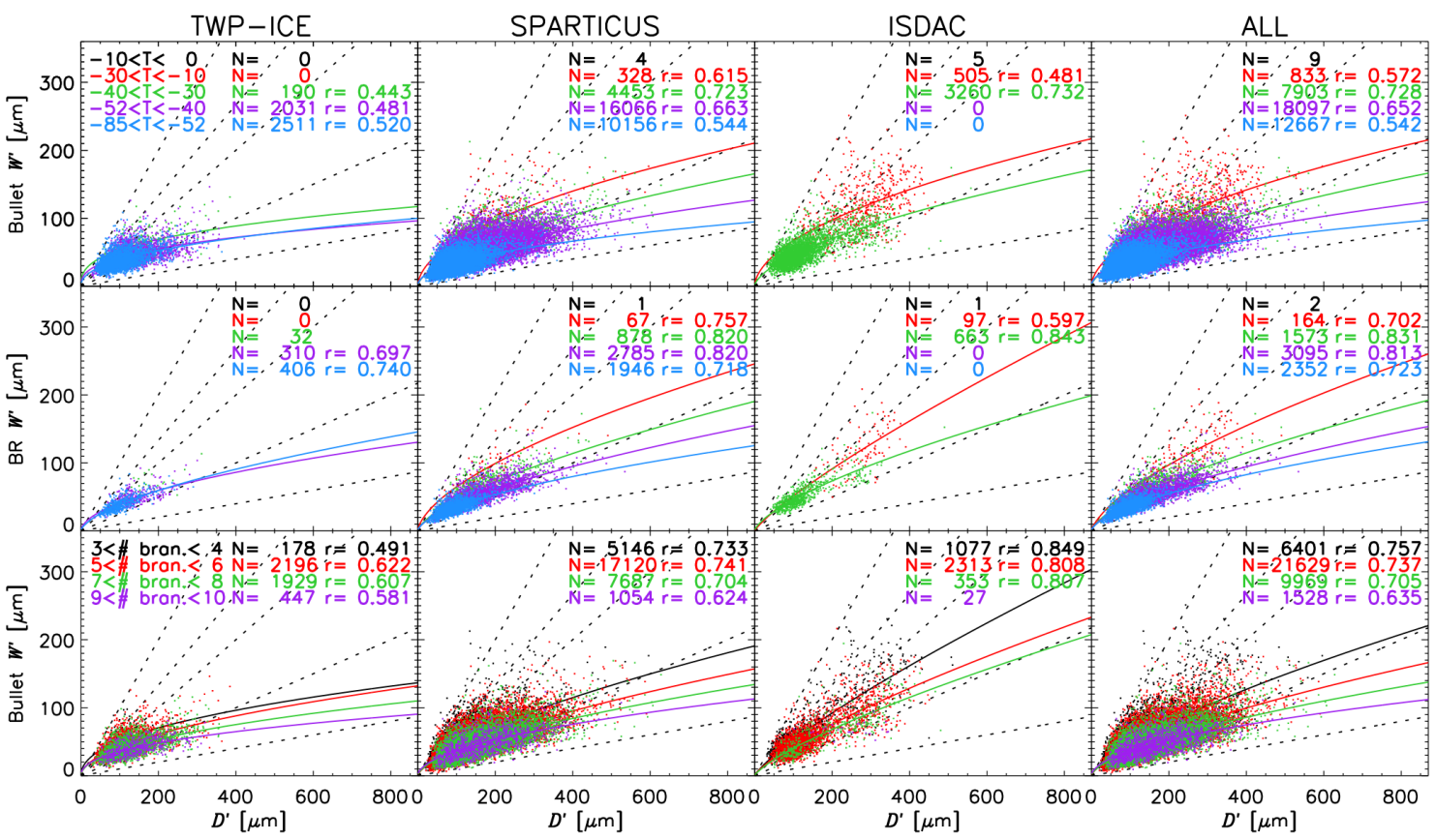

Figure 11. The $D^{\prime}-W^{\prime}$ relationship of bullets (top row) and bullet rosettes (middle row) as a function of temperature. The bottom row shows the $D^{\prime}-W^{\prime}$ relationship of bullets as a function of the number of branches in each bullet rosette.

$-35<T<-30^{\circ} \mathrm{C}$ and the number of branches in bullet rosettes at $-30<T<-25^{\circ} \mathrm{C}$.

The most prominent difference between different geophysical locations is in the relative habit fractions of pristine crystals. The relative fraction of occurrence for plates is much higher for TWP-ICE (i.e., $42.4 \%$ ) than for SPARTICUS (i.e., $7.9 \%$ ) at $-67<T<-35^{\circ} \mathrm{C}$, whereas the relative fraction of occurrence for bullet rosettes is higher for SPARTICUS (i.e., $44.2 \%$ ) than for TWP-ICE (i.e., $17.1 \%$ ) as shown in Table 7. At $-40<T<-15^{\circ} \mathrm{C}$, the relative frac- 


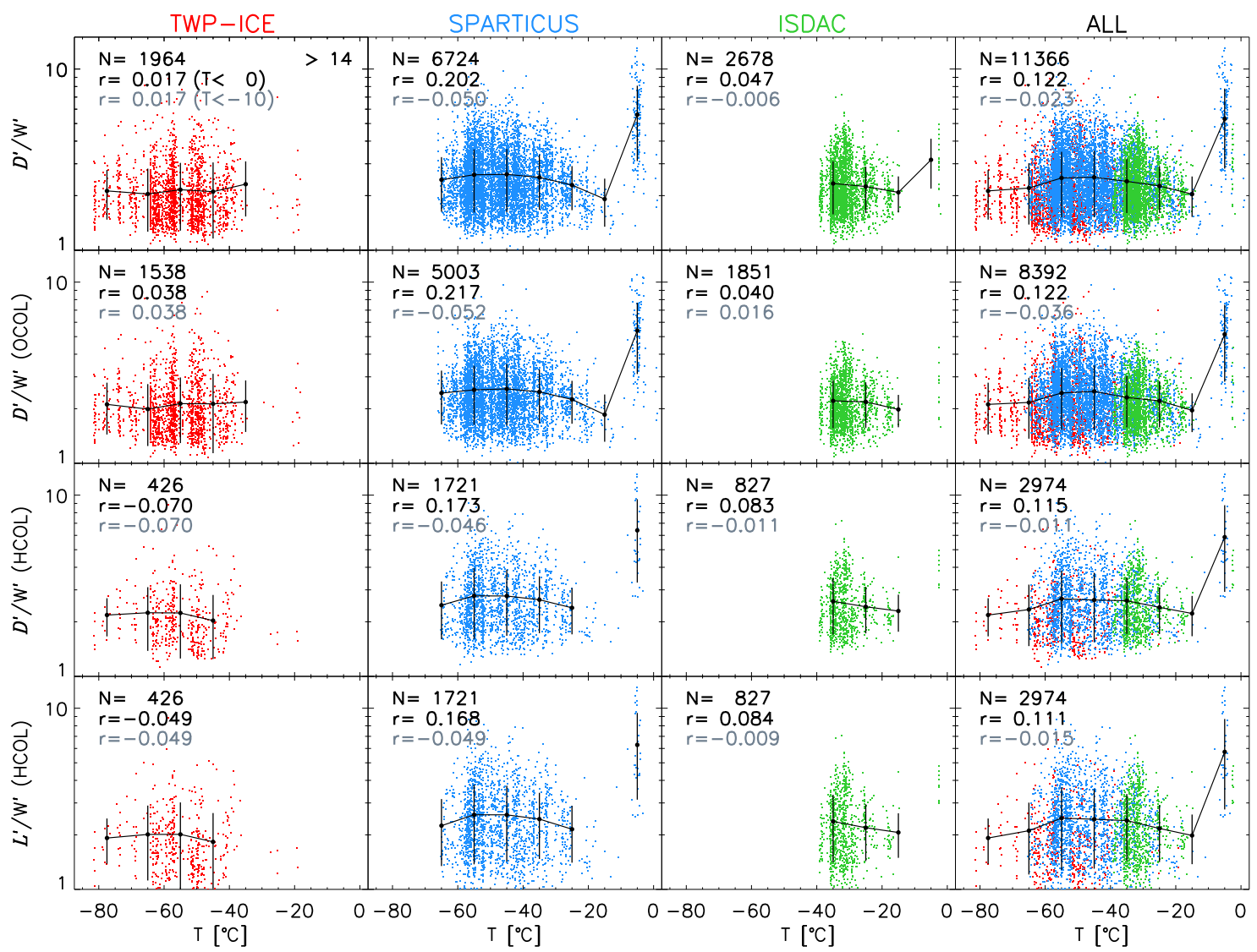

Figure 12. The projected aspect ratio $\left(D^{\prime} / W^{\prime}\right)$ of all columns (top row), oriented columns (second row, OCOL), and horizontal columns (third row, HCOL) as a function of temperature. The bottom row shows $L^{\prime} / W^{\prime}$ of horizontal columns. The mean and standard deviation for each temperature range are shown when more than 14 data points are available in the given temperature bin. Correlation coefficients $(r)$ for $-85<T<0{ }^{\circ} \mathrm{C}$ (black) and for $-85<T<-10^{\circ} \mathrm{C}$ (gray) are embedded in each panel.

tion of columns from ISDAC (i.e., 70.7\%) is higher than that from SPARTICUS (i.e., $45.5 \%$ ), with the later fraction comparable to that (i.e., $47.9 \%$ ) for $-67<T<-35^{\circ} \mathrm{C}$ for SPARTICUS. The relative fraction of plates (i.e., $9.0 \%$ ) is low for ISDAC and might be due to the selection of pristine crystals only. There is no doubt that the systems sampled had a large influence on these habit fractions. Sampling of more clouds at a variety of locations associated with different meteorological forcings would give more information on controls of these habit mixtures that need to be known for use in satellite retrieval schemes (e.g., Baum et al., 2011) and parameterizations of simple scattering properties (e.g., McFarquhar et al., 2002).

Table 7 also separates the relative fraction of occurrence (numbers in parentheses) of each habit for anvil and nonanvil clouds, respectively. At $-67<T<-35^{\circ} \mathrm{C}$, the difference in plate fraction between TWP-ICE and SPARTICUS becomes smaller for anvil and non-anvil clouds compared to the difference averaged over all clouds. The dependence of plate fraction on the type of cirrus (anvil vs. non-anvil) is also shown in the comparison between SPARTICUS and IS-
DAC fractions at $-40<T<-15^{\circ} \mathrm{C}$. In non-anvil clouds, the plate fraction from SPARTICUS of $10.6 \%$ is comparable to that from ISDAC (i.e., 9.0\%) for non-anvil clouds. Higher fractions of occurrence of plates in anvil clouds are also shown in all campaign data $\left(-85<T<0{ }^{\circ} \mathrm{C}\right)$. The relative fraction of occurrence of columns (plates; bullet rosettes) was $40.92(43.49 ; 15.59) \%, 48.37(10.78 ; 40.85) \%$, and $70.72(9.19 ; 20.09) \%$ in all clouds for TWP-ICE, SPARTICUS, and ISDAC, respectively. These numbers were 33.12 $(60.19 ; 6.69) \%, 39.33(38.60 ; 22.07) \%$, and $0(0 ; 0) \%$ for anvil clouds, and $58.20(6.50 ; 35.30) \%, 50.20$ (5.17; $44.63) \%$, and $70.72(9.19 ; 20.09) \%$ for non-anvil clouds.

However, the influence of cirrus type on the dimensions of pristine ice crystals is not straightforward. The average $D^{\prime}(\mu \mathrm{m})$ of crystals (columns; plates; bullets) in non-anvil clouds $(154.0 ; 122.3 ; 132.6)$ are larger than those in anvil clouds $(109.8 ; 104.0 ; 99.9)$ during TWP-ICE, whereas those in anvil clouds $(187.2 ; 117.5 ; 158.5)$ are larger than those in non-anvil clouds $(158.1 ; 116.3 ; 132.8)$ during SPARTICUS at $-67<T<-35^{\circ} \mathrm{C}$. 


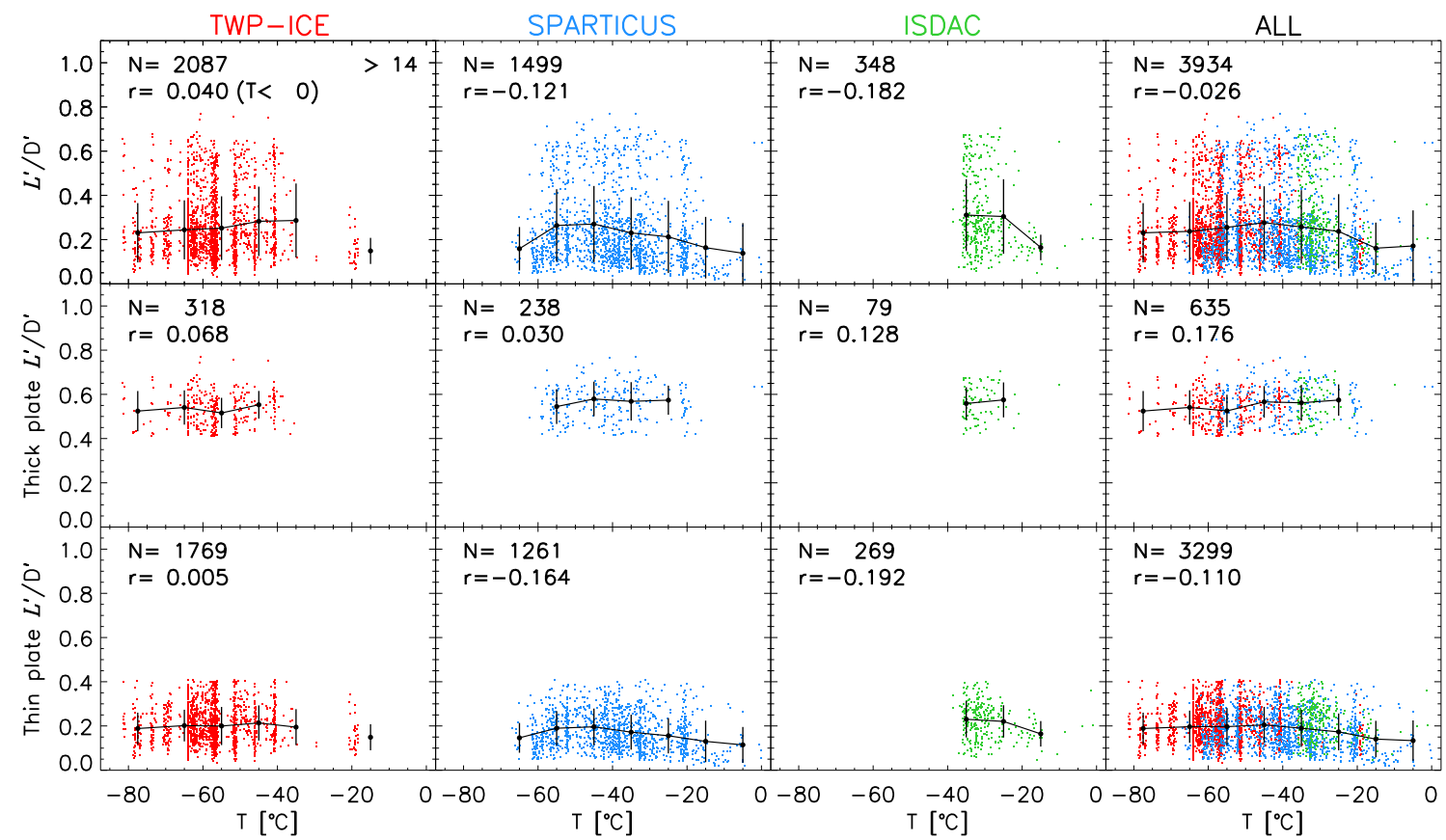

Figure 13. The projected aspect ratio $\left(L^{\prime} / D^{\prime}\right)$ of all plates (top row), thick plates (middle row), and thin plates (bottom row) as a function of temperature. The correlation coefficient $(r)$ for $-85<T<0{ }^{\circ} \mathrm{C}$ is embedded in each panel.

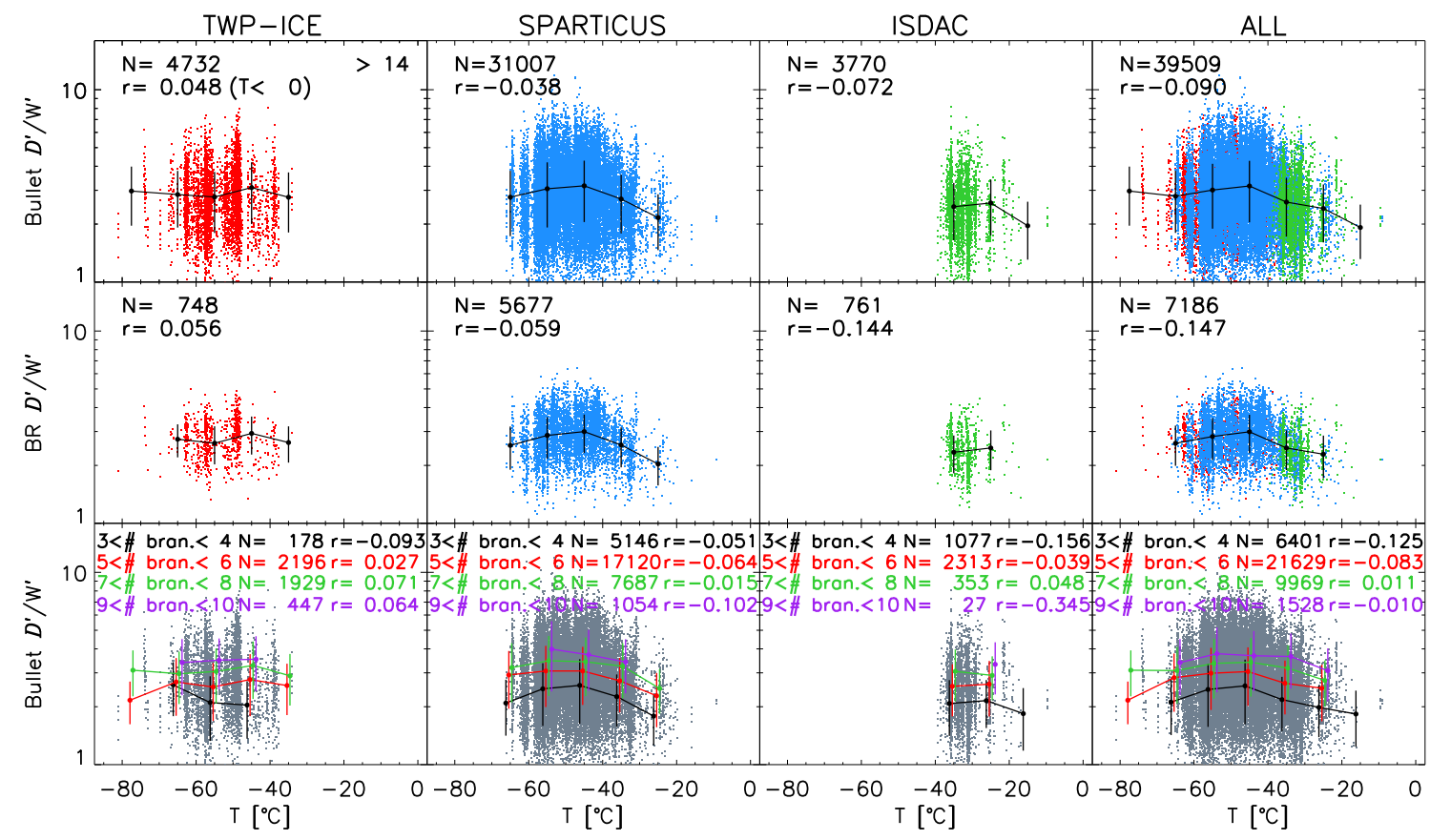

Figure 14. The projected aspect ratio $\left(D^{\prime} / W^{\prime}\right)$ of bullets (top row) and bullet rosettes (middle row) as a function of temperature, whereas the bottom row shows the dependence of $D^{\prime} / W^{\prime}$ of individual bullets on the number of branches in a bullet rosette. The data in the bottom row are gridded by temperature and offset for clarity.

In summary, most dimensions and ARs of ice crystals obtained during SPARTICUS are larger than those measured during TWP-ICE and ISDAC at $-67<T<-35^{\circ} \mathrm{C}$ and $-40<T<-15^{\circ} \mathrm{C}$, respectively, except for the ARs of plates. The number of branches in bullet rosettes is largest for TWP-ICE and smallest for ISDAC. The fraction of plates 


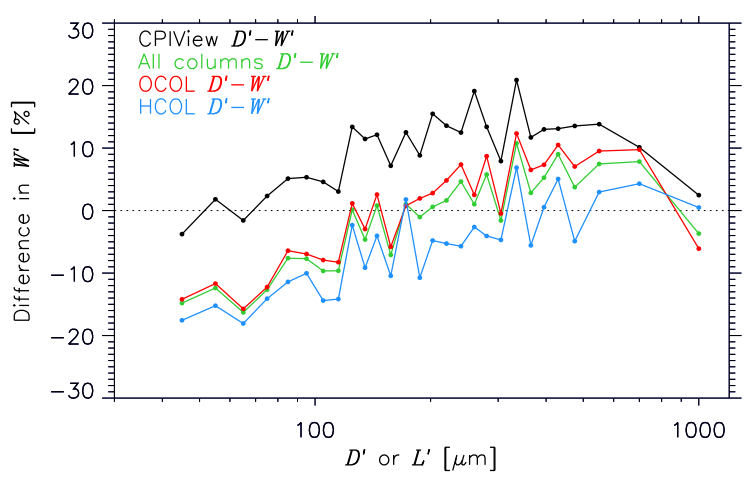

Figure 15. Calculated differences between $W^{\prime}$ s of HCOLs derived from $L^{\prime}-W^{\prime}$ relationships for HCOLs and four different $W^{\prime} \mathrm{s}$ derived from $D^{\prime}-W^{\prime}$ relationships (i.e., CPIView, all columns, OCOLs, and HCOLs) for the same $D^{\prime}$ corresponding to the $L^{\prime}$ of HCOLs. Differences are calculated as $100 \times\left(W^{\prime}\right.$ of $y-W^{\prime}$ of HCOL $\left(L^{\prime}-W^{\prime}\right.$ relationship) $) /\left(W^{\prime}\right.$ of HCOL $\left(L^{\prime}-W^{\prime}\right.$ relationship $\left.)\right)$, where four different $y$ relationships are indicated in the figure legend.

shows a strong dependence on the type of cirrus, and is much higher in anvil clouds compared to non-anvil clouds for TWP-ICE and SPARTICUS, which agrees with previous studies (e.g., Connolly et al., 2005; Um and McFarquhar, 2009; Lawson et al., 2010). In general, crystal dimensions are found to increase with temperature (e.g., Fig. 16). This is consistent with bulk ice sizes increasing with temperature as observed in situ (e.g., Lawson et al., 2010) and from satellite measurements (e.g., Yuan and Li, 2010; van Diedenhoven et al., 2014b). Furthermore, the general weak dependence of crystal aspect ratio on temperature shown in Fig. 16 is consistent with the remote sensing results of van Diedenhoven et al. (2014b).

\subsection{Comparison with previous studies}

Ice crystals are measured for their orientations with respect to the imaging plane of the CPI, with the orientations thus depending on the flow of air inside the sample tube. Because the CPI images are silhouettes, the measured dimensions and determined ARs of ice crystals are also those of silhouettes. This is true for all ice crystal images obtained by imaging probes (e.g., CPI and optical array probes). Although differences in the measured particle size from the actual maximum dimension of a spherical particle would be minimal, the differences for prolate and oblate particles, such as columns and plates, can be larger. In this study, horizontally oriented columns (HCOL) and oriented columns (OCOL) were distinguished as shown in Fig. 2b. When a column is oriented horizontally with respect to the imaging plane (the lower three images in Fig. 2b), differences from the actual maximum dimensions are much smaller than those for columns with other orientations (the upper three images in Fig. 2b). Thus, the measured dimensions and ARs of HCOLs from the current data sets were used for comparisons against those from previ- ous studies. However, the effect of orientations on the dimensions and ARs of crystals in previous studies based mostly on replicas of ice crystals, and the corresponding uncertainties in replica data, were not well quantified.

Figure 17a shows the $L$ and $W$ of HCOLs (gray squares) and $L-W$ relationships of columns determined in previous studies as summarized in Table 1. The ice crystals in previous studies were sampled over many different temperature ranges. For example, Auer and Veal (1970, AV70) determined the $L-W$ relationship (solid purple) of columns sampled in cold $\left(T<-20^{\circ} \mathrm{C}\right)$ and warm $\left(-10<T<-8^{\circ} \mathrm{C}\right)$ regimes separately. Mitchell and Arnott (1994, MA94) reanalyzed columns in the warm region sampled by AV70 and found a slightly different $L-W$ relationship of columns with $L>200 \mu \mathrm{m}$. Heymsfield (1972, HF72) derived a $L-W$ relationship of columns based on airborne measurements obtained at $-20<T<-18^{\circ} \mathrm{C}$. Interestingly, the $L-W$ relationship of columns with $L>200 \mu \mathrm{m}$ by $\mathrm{H} 72$ is the same as that of AV70. Hobbs et al. $(1974$, H74) determined $L-W$ relationships of sheaths and long solid columns (red solid line) and of solid and hollow columns (red dash line). Davis (1974, D74) combined several studies to determine $L-W$ relationships of solid columns (yellow lines) and hollow columns (sky blue lines). They were further categorized by the selection of AR of 2.0. For given $L, W$ of solid columns (dash yellow) is larger than that of hollow columns (solid blue) with $\mathrm{AR}<2.0$, whereas they are almost identical for $\mathrm{AR}>2.0$. Baker and Lawson (2006) determined the $L-W$ relationships of pristine columns observed in wave clouds $\left(-60<T<-17^{\circ} \mathrm{C}\right)$. They showed that most ARs $(L / W)$ of columns were between 1.0 and 4.0, with a mean of $\sim 2.0$. All $L-W$ relationships from previous studies fall within the range derived from the measurements of crystals in the current study and, in part, they could be reproduced using the current HCOL data when restricting them to the appropriate temperature and aspect ratio ranges of the relevant previous studies (figure not shown). This study represents the first time such relationships were confirmed using data obtained from the same probe and analyzed in a self-consistent manner.

In Fig. 17b, $L-W$ relationships of columns are quantified in four different temperature ranges using HCOL data. The $L-W$ relationship was not derived for $-20<T<0^{\circ} \mathrm{C}$ because only 42 HCOLs were sampled over these $T$. As previously shown, there is strong dependence of the $L-W$ relationships on $T$. For a given $L, W(\mathrm{AR})$ increases (decreases) with temperature. The $L-W$ relationship at $-85<T<0^{\circ} \mathrm{C}$ is closer to that at $-40<T<-20^{\circ} \mathrm{C}$ compared with those at colder temperatures $\left(-85<T<-40^{\circ} \mathrm{C}\right)$, although the number of sampled HCOLs at $-85<T<-40^{\circ} \mathrm{C}$ (1721) is larger than that at $-40<T<-20^{\circ} \mathrm{C}(1163)$. This is because the variation of $W$ for a given $L$ due to $T$ change is much larger at warmer temperatures. For example, for $300<$ $L<350 \mu \mathrm{m}$, the mean $W$ is $80.6 \pm 17.0$ and $119.7 \pm 29.6$ for $-85<T<-52$ and $-36<T<-20^{\circ} \mathrm{C}$, respectively. 


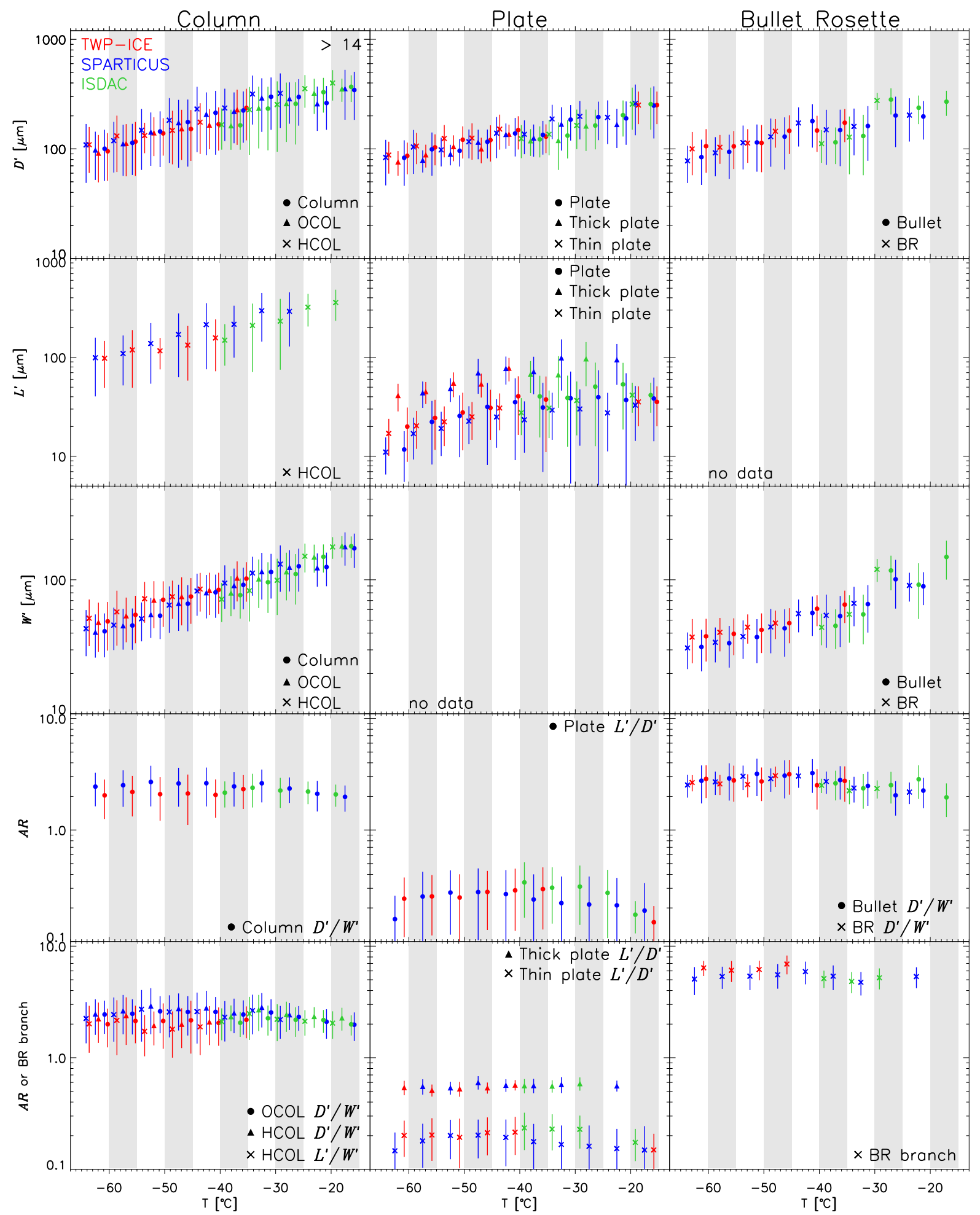

Figure 16. Mean and standard deviation of $D^{\prime}$ (top row), $L^{\prime}$ (second row), $W^{\prime}$ (third row), and aspect ratio (AR) of ice crystals for $-67<$ $T<-15^{\circ} \mathrm{C}$ when more than 14 crystals are available within each $5^{\circ} \mathrm{C}$ interval $\left(7^{\circ} \mathrm{C}\right.$ for -67 to $\left.-60^{\circ} \mathrm{C}\right)$. Plot on right of bottom row shows mean and standard deviation of number of bullets in bullet rosette. 


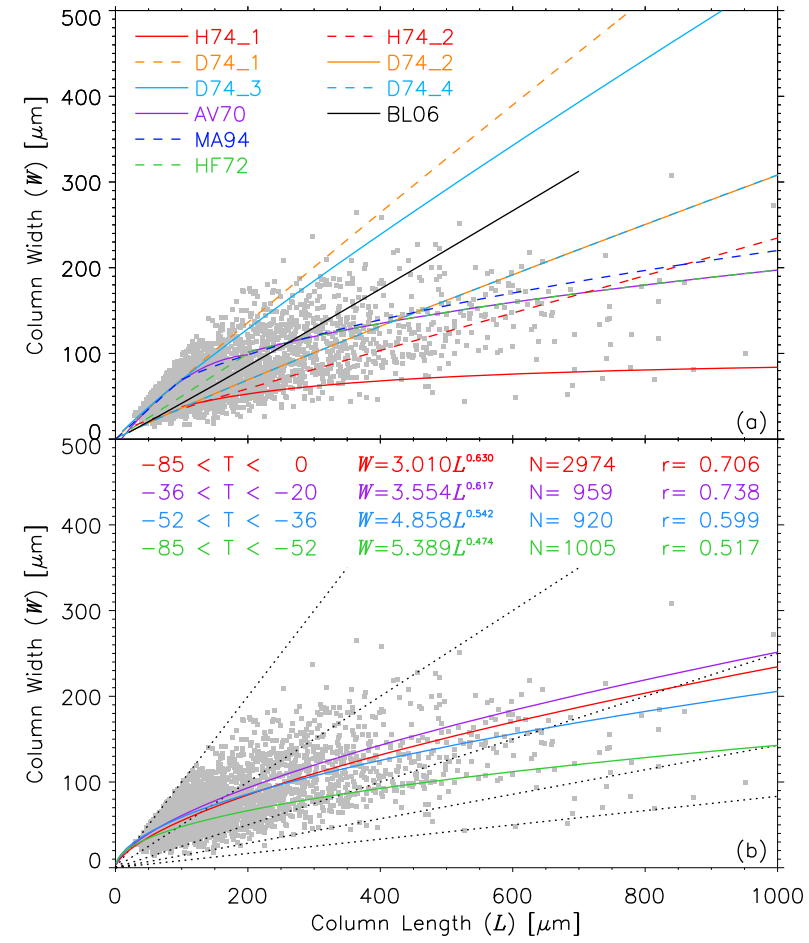

Figure 17. Comparisons between derived $L-W$ relationships of horizontal orientation columns (HCOL) and those of previous studies: AV70 (Auer and Veal, 1970), HF72 (Heymsfield, 1972), H74 (Hobbs et al., 1974), D74 (Davis, 1974), MA94 (Mitchell and Arnott, 1994), and BL06 (Baker and Lawson, 2006). Information on $L-W$ relationships from previous studies is summarized in Table 1. $L$ and $W$ of horizontally oriented columns (HCOL) from this study are shown with gray squares in each panel. (a) $L-W$ relationships from previous studies and HCOL data. (b) Derived $L-W$ relationships of columns using $\mathrm{HCOL}$ data as a function of temperature. Dotted lines representing $L / W=1,2,4,7$, and 12 are shown in (b).

\section{Summary and conclusions}

High-resolution images of ice crystals were recorded by the Cloud Particle Imager (CPI) during the 2006 Tropical Warm Pool International Cloud Experiment (TWP-ICE) in the tropics, the 2008 Indirect and Semi-Direct Aerosol Campaign (ISDAC) in the Arctic, and the 2010 Small PARTicles In CirrUS (SPARTICUS) campaign at mid-latitudes. The ice crystals were acquired at $-81.5<T<-18.3,-66.9<T<$ 0.0 , and $-39.4<T<-1.0^{\circ} \mathrm{C}$ during TWP-ICE, SPARTICUS, and ISDAC, respectively. New software, the Ice Crystal Ruler (IC-Ruler), was developed to measure the projected dimensions of pristine single ice crystals from CPI images. The projected maximum dimension $\left(D^{\prime}\right)$, width $\left(W^{\prime}\right)$, and length $\left(L^{\prime}\right)$ of columns, plates, and bullets, and the number of branches of each bullet rosette, were measured. The dimensions of $11383(1977 ; 6728 ; 2678)$ columns and 3936 $(2088 ; 1500 ; 348)$ plates imaged by the CPI version 2.0 dur- ing three field campaigns (TWP-ICE; SPARTICUS; ISDAC) were measured using the IC-Ruler. In addition, 7189 (751; $5677 ; 761)$ bullet rosettes and $39527(4750 ; 31007 ; 3770)$ component bullets were analyzed to determine their dimensions. The $L-W$ relationship or aspect ratio (AR) of each crystal habit was quantified as a function of temperature, geophysical location (tropics, mid-latitudes, and Arctic), and type of cirrus (e.g., anvil and non-anvil). The principal findings of this study are summarized as follows.

1. The maximum occurrence frequency of bullet rosettes occurred at $T \sim-45^{\circ} \mathrm{C}$. Plates showed exactly the opposite pattern, with a minimum occurrence frequency at $T \sim-45^{\circ} \mathrm{C}$. Column crystals were ubiquitous for all temperature ranges even in the plate formation regime of $-40<T<-20^{\circ} \mathrm{C}$.

2. The dimensions of ice crystals showed a strong dependence on temperature. All measured dimensions of columns, plates, and bullets increased with temperature, except for the $W^{\prime}$ of columns, which decreased between -10 and $0{ }^{\circ} \mathrm{C}$ during SPARTICUS and ISDAC. The columns measured at such temperatures were grown in mixed-phase clouds where needles, sheaths, and long columns can grow.

3. Columnar crystals (i.e., columns and bullets) have larger dimensions (i.e., $W^{\prime}$ ) of the minor axis (i.e., $a$ axis) for a given dimension (i.e., $D^{\prime}$ or $L^{\prime}$ ) of the major axis (i.e., $c$ axis), and thus smaller AR, as temperature increases. This trend was not noted for plate crystals.

4. The AR of columnar crystals increased with the dimension of the major and minor axes, albeit at a reduced rate for larger crystal dimensions. The AR of columns showed a weak temperature dependence, with broad maxima at $-55<T<-45^{\circ} \mathrm{C}$. The AR of columns showed a sharp peak at $T \sim-5^{\circ} \mathrm{C}$, where long columns were sampled during SPARTICUS and ISDAC, whereas the minimum AR of plates was found at $T \sim-15^{\circ} \mathrm{C}$. The ARs of bullets and bullet rosettes slightly decreased with temperature.

5. Different definitions of dimensions of ice crystals invoked different $L-W$ relationships of ice crystals, which caused a difference of up to $14 \%$ in $W$ and hence AR of columns for given $L$. In particular, directly derived AR of columns from in situ data caused a difference of up to $21 \%$ compared with the manually determined AR.

6. The AR of bullets increased with the number of branches in the bullet rosettes. The mean and standard deviation of the numbers of bullets (i.e., branches) were $5.50 \pm 1.35$ for all three campaigns and $6.32 \pm 1.34$, $5.46 \pm 1.34$, and $4.95 \pm 1.01$ for TWP-ICE, SPARTICUS, and ISDAC, respectively. 
7. At $-67<T<-35^{\circ} \mathrm{C}$, most dimensions of ice crystals measured during SPARTICUS were larger than those of TWP-ICE and the differences in dimensions increased with temperature. The ARs of columnar crystals during SPARTICUS were larger than those from TWPICE, whereas ARs $(\sim 0.25)$ of plates were comparable. At $-40<T<-15^{\circ} \mathrm{C}$, larger dimensions and ARs of columnar crystals and smaller ARs of plates were seen for SPARTICUS compared to ISDAC.

8. The relative habit fractions of pristine crystals (i.e., columns, plates, and bullet rosettes) depend strongly on whether the clouds were anvils or not, with fractions of plates larger in anvils. For example, the relative fractions of columns (plates; bullet rosettes) were $33.1 \%$ $(60.2 ; 6.7 \%)$ and $39.3 \%(38.6 ; 22.1 \%)$ during TWPICE and SPARTICUS, respectively, in anvils, whereas they were $58.2 \%(6.5 ; 35.3 \%)$ and $50.2 \%(5.2 ; 44.6 \%)$ in non-anvil clouds.

9. The $L-W$ relationships of columns determined in previous studies were within the range of current data and, in part, could be reproduced using the current data with varying aspect ratio and temperature ranges. The $L-W$ relationships of columns were determined using horizontally oriented columns at four different temperature ranges (i.e., $-85<T<-0,-40<T<-20$, $-60<T<-40$, and $-85<T<-60^{\circ} \mathrm{C}$ ) and exhibited strong temperature dependence.

In summary, the dimensions of ice crystals increased with temperature, and the $L-W$ relationships of crystals with a given $L$ depended heavily on temperature. For a given $T$, there was wide variability in the aspect ratios of crystals. The relative frequency of occurrence of plates was much larger in anvil clouds compared to that of columnar crystals (i.e., columns and bullet rosettes), whereas the relative occurrence frequency of columnar crystals was much larger in non-anvil clouds. The $L-W$ relationships of columns determined in previous studies were within ranges of current data and, in part, could be reproduced using current data that were obtained by the same probe and analyzed in a consistent manner. Thus, the correct use of $L-W$ relationships of crystals, at least, for a desired temperature range is highly required.

In this study, a single particle database has been established and will be enlarged using in situ observations acquired under other meteorological conditions. Furthermore, the influence of particle orientations on the actual particle properties (e.g., dimensions and ARs) that is unavoidable in airborne optical array and imaging probes will be quantified in a subsequent study. Although the influence of humidity on the growth of ice crystals was not included in this study because of the unavailability of good-quality humidity measurements, future studies should examine such effects with other data sets. These large databases are essential and important to represent the wide spread of microphysical and ra- diative properties of ice crystals for retrieval algorithms and numerical modeling studies.

Acknowledgements. This research was supported by the US Department of Energy's Atmospheric System Research, an Office of Science, Office of Biological and Environmental Research program, under grant nos. DE-FG02-09ER64770, DE-SC0001279, and DE-SC0008500, and by NASA under grant no. NNX14AJ28G. US Department of Energy as part of the Atmospheric Radiation Measurement (ARM) Climate Research Facility TWP-ICE, ISDAC, and SPARTICUS data were used. We thank S. Kim and K. Yaffe for initial image analysis and B. van Diedenhoven for thoughtful comments.

Edited by: H. Grothe

\section{References}

Arnott, W. P., Dong, Y. Y., and Hallet, J.: Role of small ice crystals in radiative properties of cirrus: A case study, FIRE II, November 22, 1991, J. Geophys. Res., 99, 1371-81, 1994.

Auer, A. H. and Veal, D. L.: The dimension of ice crystals in natural clouds, J. Atmos. Sci., 27, 919-926, 1970.

aufm Kampe, H. J., Weickmann, H. K., and Kelly, J. J.: The influence of temperature on the shape of ice crystals growing at water saturation, J. Meteorol., 8, 168-174, 1951.

Bacon, N. J., Baker, M. B., and Swanson, B. D.: Initial stages in the morphological evolution of vapour-grown ice crystals: A laboratory investigation, Q. J. Roy. Meteor. Soc., 129, 1903-1927, 2003.

Bailey, M. P. and Hallett, J.: Nucleation effects on the habit of vapour grown ice crystals from -18 to $-42{ }^{\circ} \mathrm{C}$, Q. J. Roy. Meteor. Soc., 128, 1461-1483, 2002.

Bailey, M. P. and Hallett, J.: Growth rates and habits of ice crystals between $-20^{\circ} \mathrm{C}$ and $-70^{\circ} \mathrm{C}$, J. Atmos. Sci., 61, 514-44, 2004.

Bailey, M. P. and Hallett, J.: A comprehensive habit diagram for atmospheric ice crystals: Confirmation from the laboratory, AIRS II, and other field studies, J. Atmos. Sci., 66, 2888-2899, 2009.

Bailey, M. P. and Hallett, J.: Ice crystal linear growth rates from $-20^{\circ} \mathrm{C}$ to $-70^{\circ} \mathrm{C}$ : confirmation from wave cloud studies, J. Atmos. Sci., 69, 390-402, 2012.

Baker, B. A. and Lawson, R. P.: In situ observations of the microphysical properties of wave, cirrus, and anvil clouds. Part I: Wave clouds, J. Atmos. Sci., 63, 3160-3185, 2006.

Baran, A. J.: From the single-scattering properties of ice crystals to climate prediction: a way forward, Atmos. Res., 112, 45-69, 2012.

Baran, A. J., Francis, P. N., Labonnote, L. C., and DoutriauxBoucher, M.: A scattering phase function for ice cloud: Tests of applicability using aircraft and satellite multi-angle multiwavelength radiance measurements of cirrus, Q. J. Roy. Meteor. Soc., 127, 2395-416, 2001.

Baran, A. J., Shcherbakov, V., Barker, B. A., Gayet, J.-F., and Lawson, R. P.: On the scattering phase-function of non-symmetric ice-crystals, Q. J. Roy. Meteor. Soc., 131, 2609-2616, 2005.

Baum, B. A., Yang, P., Heymsfield, A. J., Schmitt, C. G., Xie, Y., Bansemer, A., Hu, Y.-X., and Zhang, Z.: Improvements in short- 
wave bulk scattering and absorption models for the remote sensing of ice clouds, J. Appl. Meteorol. Clim., 50, 1037-1056, 2011.

Cole, B. H., Yang, P., Baum, B. A., Riedi, J., and C.-Labonnote, L.: Ice particle habit and surface roughness derived from PARASOL polarization measurements, Atmos. Chem. Phys., 14, 37393750, doi:10.5194/acp-14-3739-2014, 2014.

Connolly, P. J., Saunders, C. P. R., Gallagher, M. W., Bower, K. N., Flynn, M. J., Choularton, T. W., Whiteway, J., and Lawson, R. P.: Aircraft observations of the influence of electric fields on the aggregation of ice crystals, Q. J. Roy. Meteor. Soc., 131, 16951712,2005

Davis, C. I.: The ice-nucleating characteristics of various AgI aerosols, PhD Dissertation, University of Wyoming, 267 pp., 1974.

Dearden, C., Connolly, P. J., Choularton. T., Field, P. R., and Heymsfield, P. R.: Factors influencing ice formation and growth in simulations of a mixed-phase wave cloud, J. Adv. Model. Earth Syst., 4, M10001, doi:10.1029/2012MS000163, 2012.

DeVore, J. G., Stair Jr., A. T., LePage, A. J., and Vallanucci, D.: Using scattering calculations to compare MODIS retrievals of thin cirrus optical properties with SAM solar disk and aureole radiance measurements, J. Geophys. Res., 117, D01204, doi:10.1029/2011JD015858, 2012.

Dowling, D. R. and Radke, L. F.: A summary of the physical properties of cirrus clouds, J. Appl. Meteorol., 29, 970-978, 1990.

$\mathrm{Fu}, \mathrm{Q}$.: An accurate parameterization of the solar radiative properties of cirrus clouds, J. Climate, 9, 2058-2082, 1996.

$\mathrm{Fu}, \mathrm{Q}$.: A new parameterization of an asymmetry factor of cirrus clouds for climate models, J. Atmos. Sci., 64, 4140-4150, 2007.

Fukuta, N. and Takahashi, T.: The growth of atmospheric ice crystals: a summary of findings in vertical supercooled cloud tunnel studies, J. Atmos. Sci., 56, 1963-1979, 1999.

Gonda, T.: The influence of the diffusion of vapor and heat on the morphology of ice crystals grown from the vapor, J. Cryst. Growth, 49, 173-181, 1980.

Goodman, J., Toon, O. B., Pueschel, R. F., Snetsinger, K. G., and Verma, S.: Antarctic stratospheric ice crystals, J. Geophys. Res., 94, 16449-16457, 1989.

Hallett, J.: The growth of ice crystals on freshly cleaved covellite surface, Philos. Mag., 6, 1073-1087, 1961.

Hallett, J.: Field and laboratory observations of ice crystal growth from the vapor, J. Atmos. Sci., 22, 64-69, 1965.

Hallett, J. and Mason, B. J.: The influence of temperature and supersaturation on the habit of ice crystals frown from the vapour, P. Roy. Soc. A, 247, 440-453, 1958.

Han, Q. Y., Rossow, W. B., Chou, J., Kuo, K. S., and Welch, R. M.: The effects of aspect ratio and surface roughness on satellite retrievals of ice-cloud properties, J. Quant. Spectrosc. Ra., 63, 559583,1999

Heymsfield, A. J.: Ice crystal terminal velocities, J. Atmos. Sci., 29, 1348-1357, 1972.

Heymsfield, A. J. and McFarquhar, G. M.: Mid-Latitude and Tropical Cirrus Microphysical Properties, edited by: Lynch, D., Cirrus, Oxford University Press, New York, USA, 78-101, 2002.

Hobbs, P. V., Chang, S., and Locatelli, J. D.: The dimensions and aggregation of ice crystals in natural clouds, J. Geophys. Res., 79, 2199-2206, 1974.

IPCC: Climate Change 2013: The physical science basis. Contribution of Working Group I to the Fifth Assessment Report of the Intergovernmental Panel on Climate Change, edited by: Stocker, T. F., Qin, D., Plattner, G.-K., Tignor, M., Allen, S. K., Boschung, J., Nauels, A., Xia, Y., Bex, V., and Midgley, P. M., Cambridge University Press, Cambridge, UK and New York, NY, USA, 2013.

Isono, K.: Microphysical processes in precipitation mechanism, J. Meteorol. Soc. Jpn., 37, 135, 1959.

Kajikawa, M.: Measurement of falling velocity of individual snow crystals, J. Meteorol. Soc. Jpn., 50, 577-584, 1972.

Korolev, A. V., Isaac, G. A., and Hallett, J.: Ice particle habits in Arctic clouds, Geophys. Res. Lett., 26, 1299-1302, 1999.

Korolev, A. V. and Isaac, G. A.: Roundness and aspect ratio of particles in ice clouds, J. Atmos. Sci., 60, 1795-1808, 2003.

Korolev, A. V., Bailey, M. P., Hallett, J., and Isaac, G. A.: Laboratory and in situ observation of deposition growth of frozen drops, J. Appl. Meteorol., 43, 612-622, 2004

Lamb, D. and Hobbs, P. V.: Growth rates and habits of ice crystals grown from the vapor phase, J. Atmos. Sci., 28, 1506-1509, 1971.

Lamb, D. and Scott, W. D.: The mechanism of ice crystal growth and habit formation, J. Atmos. Sci., 31, 570-580, 1974.

Lawson, R. P., Baker, B. A, Schmitt, C. G., and Jensen, T. L.: An overview of microphysical properties of Arctic clouds observed in May and July 1998 during FIRE ACE, J. Geophys. Res., 106, 14989-15014, doi:10.1029/2000JD900789, 2001.

Lawson, R. P., Baker, B., Pilson, B., and Mo, Q.: In situ observations of the microphysical properties of wave, cirrus, and anvil clouds. Part II: Cirrus clouds, J. Atmos. Sci., 63, 3186-3203, 2006.

Lawson, R. P., Jensen, E., Mitchell, D. L., Baker, B., Mo, Q., and Pilson, B.: Microphysical and radiative properties of tropical clouds investigated in TC4 and NAMMA, J. Geophys. Res., 115, D00J08, doi:10.1029/2009JD013017, 2010.

Liou, K. N.: Influence of cirrus clouds on weather and climate processes: a global perspective, Mon. Weather Rev., 114, $1167-$ 1199, 1986.

Macke, A., Mueller, J., and Raschke, E.: Single scattering properties of atmospheric ice crystals, J. Atmos. Sci., 53, 2813-2825, 1996.

Magono, C.: On the falling velocity of solid precipitation elements, Sci. Repts. Yokohama Natl. Univ. Sect. I., 3, 33-40, 1954.

Magono, C. and Lee, C. W.: Meteorological classification of natural snow crystals, J. Fac. Sci. Hokkaido Univ. Series VII, 2, $321-$ 335, 1966.

Mann, H. B. and Whitney, D. R.: On a test of whether one of two random variables is stochastically larger than the other, Ann. Math. Stat., 18, 50-60, 1947.

Mason, B. J.: The growth of ice crystals in a supercooled water cloud, Q. J. Roy. Meteor. Soc., 79, 104-111, 1953.

May, P. T., Mather, J. H., Vaughan, G., Jakob, C., McFarquhar, G. M., Bower, K. N., and Mace, G. G.: The tropical warm pool international cloud experiment, B. Am. Meteorol. Soc., 89 , 629-645, 2008.

McFarquhar, G. M., Yang, P., Macke, A., and Baran, A. J.: A new parameterization of single-scattering solar radiative properties for tropical ice clouds using observed ice crystal size and shape distributions, J. Atmos. Sci., 59, 2458-2478, 2002.

McFarquhar, G. M., Ghan, S., Verlinde, J., Korolev, A., Strapp, J. W., Schmid, B., Tomlinson, J. M., Wolde, M., Brooks, S. D., Cziczo, D., Dubey, M. K., Fan, J., Flynn, C., Gultepe, I., Hubbe, J., Gilles, M. K., Laskin, A., Lawson, P., 
Leaitch, W. R., Liu, P., Liu, X., Lubin, D., Mazzoleni, C., Macdonald, A.-M., Moffet, R. C., Morrison, H., Ovchinnikov, M., Shupe, M. D., Turner, D. D., Xie, S., Zelenyuk, A., Bae, K., Freer, M., and Glen, A.: Indirect and semi-direct aerosol campaign, B. Am. Meteorol. Soc., 92, 183-201, 2011.

McFarquhar, G. M., Um, J., and Jackson, R.: Small cloud particle shapes in mixed-phase clouds, J. Appl. Meteorol. Clim., 52, 1277-93, 2013.

Mitchell, D. L. and Arnott, W. P.: A model predicting the evolution of ice particle size spectra and radiative properties of cirrus clouds. Part II: Dependence of absorption and extinction on ice crystal morphology, J. Atmos. Sci., 51, 817-832, 1994.

Nakaya, U.: Snow Crystals: Natural and Artificial, Harvard University Press, Cambridge, USA, 510 pp., 1954.

Ono, A.: The shape and riming properties of ice crystals in natural clouds, J. Atmos. Sci., 26, 138-47, 1969.

Ono, A.: Growth mode of ice crystals in natural clouds, J. Atmos. Sci., 27, 649-58, 1970.

Reynolds, S. E.: Ice-crystal growth, J. Meteorol., 9, 36-40, 1952.

Schaefer, V. J.: Properties of particles of snow and the electrical effects they produce in storms, EOS T. Am. Geophys. Un., 28, 587-614, 1947.

Sheridan, L. M., Harrington, J. Y., Lamb, D., and Sulia, K.: Influence of ice crystal aspect ratio on the evolution of ice size spectra during vapor depositional growth, J. Atmos. Sci., 66, 3732-3743, 2009.

Sulia, K. J. and Harrington, J. Y.: Ice aspect ratio influences on mixed-phase clouds: Impacts on phase partitioning in parcel models, J. Geophys. Res., 116, D21309, doi:10.1029/2011JD016298, 2011.

Takano, Y. and Liou, K. N.: Radiative transfer in cirrus clouds. Part III: Light scattering by irregular ice crystals, J. Atmos. Sci., 52, 818-837, 1995.

Um, J. and McFarquhar, G. M.: Single-scattering properties of aggregates of bullet rosettes in cirrus, J. Appl. Meteorol. Clim., 46, 757-775, 2007.

Um, J. and McFarquhar, G. M.: Single-scattering properties of aggregates of plates, Q. J. Roy. Meteor. Soc., 135, 291-304, 2009.

Um, J. and McFarquhar, G. M.: Dependence of the single-scattering properties of small ice crystals on idealized shape models, Atmos. Chem. Phys., 11, 3159-3171, doi:10.5194/acp-11-31592011, 2011.

Um, J. and McFarquhar, G. M.: Optimal numerical methods for determining the orientation averages of single-scattering properties of atmospheric ice crystals, J. Quant. Spectrosc. Ra., 127, 207223, doi:10.1016/j.jqsrt.2013.05.020, 2013.

van Diedenhoven, B., Cairns, B., Geogdzhayev, I. V., Fridlind, A. M., Ackerman, A. S., Yang, P., and Baum, B. A.: Remote sensing of ice crystal asymmetry parameter using multi-directional polarization measurements - Part 1: Methodology and evaluation with simulated measurements, Atmos. Meas. Tech., 5, 23612374, doi:10.5194/amt-5-2361-2012, 2012. van Diedenhoven, B., Ackerman, A. S., Cairns, B., and Fridlind, A. M.: A flexible parameterization for shortwave optical properties of ice crystals, J. Atmos. Sci., 71, 1763-1782, 2014a.

van Diedenhoven, B., Fridlind, A. M., Cairns, B., and Ackerman, A. S.: Variation of ice crystal size, shape and asymmetry parameter in tops of tropical deep convective clouds. J. Geophys. Res.-Atmos., 119, 11809-11825, doi:10.1002/2014JD022385, 2014b.

Walden, V. P., Warren, S. G., and Tuttle, E.: Atmospheric ice crystals over Antarctic plateau in winter, J. Appl. Meteorol., 42, 1391-1405, 2003.

Weickmann, H.: The Ice Phase in the Atmosphere, Library Translation 273, Royal Aircraft Establishment, 96 pp., 1948 (in German).

Wilcoxon, F.: Individual comparisons by ranking method, Biometrics Bull., 1, 80-83, 1945.

Yang, P. and Fu, Q.: Dependence of ice crystal optical properties on particle aspect ratio, J. Quant. Spectrosc. Ra., 110, 1604-1614, 2009.

Yang, P. and Liou, K. N.: Single-scattering properties of complex ice crystals in terrestrial atmosphere, Contrib. Atmos. Phys., 71, 223-248, 1998.

Yang, P., Wei, H., Huang, H.-L., Baum, B. A., Hu, Y. X., Kattawar, G. W., Mishchenko, M. I., and Fu, Q.: Scattering and absorption property database for nonspherical ice particles in the near- through far-infrared spectral region, Appl. Optics, 44, 5512-5523, 2005.

Yang, P., Bi, L., Baum, B. A., Liou, K.-N., Kattawar, G. W., Mishchenko, M. I., and Cole, B.: Spectrally consistent scattering, absorption, and polarization properties of atmospheric ice crystals at wavelengths from 0.2 to $100 \mu \mathrm{m}$, J. Atmos. Sci., 70, 330-347, 2013.

Yi, B., Yang, P., Baum, B. A., L'Ecuyer, T., Oreopoulos, L., Mlawer, E. J., Heymsfield, A. J., and Liou, K.-N.: Influence of ice particle surface roughening on the global cloud radiative effect, J. Atmos. Sci., 70, 2794-2807, 2013.

Yuan, T. and Li, Z.: General macro- and microphysical properties of deep convective clouds as observed by MODIS, J. Climate, 23, 3457-3473, doi:10.1175/2009JCLI3136.1, 2010.

Zhang, K., Liu, X., Wang, M., Comstock, J. M., Mitchell, D. L., Mishra, S., and Mace, G. G.: Evaluating and constraining ice cloud parameterizations in CAM5 using aircraft measurements from the SPARTICUS campaign, Atmos. Chem. Phys., 13, 4963-4982, doi:10.5194/acp-13-4963-2013, 2013. 